\title{
Infecciones más comunes en el paciente trasplantado
}

\section{The most common infections in the transplanted patient}

\author{
J. R.Yuste, J. L. del Pozo, E. G. Quetglás, J. R. Azanza
}

\section{RESUMEN}

El trasplante es uno de los avances médicos más importante $\mathrm{y}$, actualmente, sigue representando la única esperanza terapéutica de muchas enfermedades. Sin embargo, existen factores asociados al trasplante, como los estados de neutropenia y la inmunosupresión, que favorecen la aparición de infecciones. Estas infecciones tienen peculiaridades en los pacientes trasplantados. En este sentido, existen enfermedades infecciosas que prácticamente sólo aparecen en situaciones de inmunosupresión y además, la expresión clínica de determinadas infecciones puede ser distinta a las que tendría un paciente inmunocompetente. Por otra parte, algunas infecciones, dada su elevada prevalencia, deben ser subsidiarias de estrategias preventivas ya que su aparición implica un aumento de la morbimortalidad, bien por la propia enfermedad o por la aparición de posibles episodios de rechazo asociados. Estas estrategias se inician antes del trasplante con la adecuación de pautas de vacunación tanto al propio paciente como a las personas de su entorno y se continúan tras la realización del mismo con pautas de profilaxis y de tratamiento anticipado. Dada la importancia de las infecciones en la evolución y pronóstico de los pacientes trasplantados es importante conocer la patología infecciosa asociada, sus manifestaciones clínicas y sus formas de prevención y tratamiento.

Palabras clave. Trasplante de precursores hematopoyéticos (TPH). Trasplante de órgano sólido (TOS). Infecciones. Profilaxis. Tratamiento.

An. Sist. Sanit. Navar. 2006; 29 (Supl. 2): 175-206.

\begin{abstract}
Organ transplantation has become one of the most important areas of medical research and, at present, is still the only therapeutical tool for several diseases. However, there are a number of factors related to transplantation, like immunosuppression and prolonged neutropenia that affect the incidence of infection. These infections are somehow peculiar to trasplant recipients. In fact, there are infectious diseases that only occur in immunodepression situations and, moreover, clinical expression of these infectious diseases can be quite different from that in immunocompetent patients. Besides these aspects, some infections, due to the high prevalence described, must be considered for prevention strategies because they continue to be a principal cause of morbidity and mortality, either due to direct effects or to their implication in the pathogenesis of rejection. These strategies commence before trasplantation by active immunization through vaccine administration to the patient and to people in the milieu and continue after trasplantation with prophylaxis or pre-emptive therapy. The importance of infectious diseases in the evolution and prognosis of trasplant recipients gives a special meaning to the understanding of associated infections, their clinical expression and ways of prevention and treatment.
\end{abstract}

Key words. Stem cell transplantation. Solid organ trasplantation. Infections. Prophylaxis. Treatment.
Área de Enfermedades Infecciosas. Clínica Universitaria de Navarra. Universidad de Navarra. Pamplona.

\section{Correspondencia:}

Dr. José Ramón Azanza Perea

Área de Enfermedades Infecciosas

Clínica Universitaria de Navarra

Facultad de Medicina

Universidad de Navarra

Avda. Pío XII, 36

31008 Pamplona

Tfno. 948296695

Fax. 948296500

E-mail: jrazanza@unav.es 


\section{INFECCIONES EN EL TRASPLANTE DE PRECURSORES HEMATOPOYÉTICOS (TPH)}

\section{Infecciones bacterianas}

Las infecciones bacterianas ocurren habitualmente en el período inmediato post-trasplante, suponen más del $90 \%$ de las infecciones observadas durante la fase de neutropenia y cursan con bacteriemia en aproximadamente el 30\% de los casos. Actualmente, los estafilococos coagulasa negativos (ECN) y los estreptococos del grupo viridans son los microorganismos predominantes (a diferencia de lo que ocurría hace algunos años donde los microorganismos gramnegativos suponían la mayoría de los aislamientos) ${ }^{1}$. La bacteriemia por ECN tiene su origen habitualmente en los catéteres intravasculares, sin embargo, y tras la realización de estudios de tipado molecular, se ha demostrado que el tracto gastrointestinal es otro foco importante ${ }^{2}$. Las infecciones causadas por ECN ocasionan una escasa mortalidad, pero condicionan una prolongación de la estancia media de los pacientes, un aumento del consumo de glicopéptidos y obligan a un recambio de los catéteres intravasculares en un elevado porcentaje de los casos. Los estreptococos del grupo viridans son una causa importante de bacteriemia en este grupo de pacientes (aproximadamente un $10 \%$ de éstas cursan con complicaciones graves) ${ }^{3}$. Además, en los últimos años se ha producido un aumento tanto de la resistencia de estos microorganismos a penicilina como de la sensibilidad disminuida a betalactámicos. La bacteriemia por Staphylococcus aureus tiene su origen frecuentemente en dispositivos intravasculares. En los pacientes con neumonía siempre se debe tener en cuenta a Streptococcus pneumoniae como posible agente causal. Las infecciones enterocócicas son poco frecuentes en estos pacientes, ocurren durante la fase de neutropenia y habitualmente se presentan como infecciones asociadas a catéter o infecciones con origen en el tracto gastrointestinal (en algunos centros la multirresistencia de este microorganismo supone un problema importante). Las infecciones por Listeria monocytogenes (fundamentalmente menin- goencefalitis) son poco frecuentes debido en parte al uso de cotrimoxazol para prevenir la neumonía por Pneumocystis jirove$c i$. Las infecciones por otros microorganismos grampositivos como por ejemplo Nocardia spp. son poco frecuentes. Las infecciones por bacilos gramnegativos suelen ocurrir durante la fase de neutropenia pre-injerto, tienen su origen habitualmente en el tracto gastrointestinal y son causa de una elevada mortalidad. Escherichia coli, Klebsiella pneumoniae y Pseudomonas aeruginosa son los microorganismos que se aislan con mayor frecuencia. Durante la fase tardía post-trasplante, las infecciones por Haemophilus influenzae son relativamente frecuentes. Otros microorganismos gramnegativos como Stenotrophomas maltophilia y Legionella pneumophila también tienen su importancia en estos pacientes.

\section{Infecciones fúngicas}

Las infecciones fúngicas son una causa importante de mortalidad en los pacientes sometidos a TPH, de hecho, la prevalencia de enfermedad fúngica invasora en varias series de autopsias se sitúa en torno al $25 \%$. Los hongos más frecuentemente implicados son Candida spp. (Candida albicans es la especie predominante) y Aspergillus spp. De forma ocasional pueden verse implicados Fusarium spp., Scedosporium spp., mucorales y otros hongos emergentes ${ }^{4}$. Las infecciones fúngicas ocurren habitualmente durante el período de neutropenia post-injerto, aunque las infecciones por Aspergillus spp. pueden observarse también en el período intermedio post-trasplante. La mayoría de las infecciones por levaduras corresponden a formas localizadas (muguet oral o esofagitis), desarrollando una verdadera candidemia sólo un pequeño porcentaje de pacientes (la aparición de lesiones cutáneas maculopapulares y mialgias puede orientar al diagnóstico). La presencia de dolor en hipocondrio derecho junto con cifras elevadas de fosfatasa alcalina y fiebre persistente a pesar de la recuperación de cifras de neutrófilos obliga a descartar la existencia de una candidiasis hepatoespléni$\mathrm{ca}^{5}$. La candidemia relacionada con catéter tiene mejor pronóstico que la candidemia 
diseminada. Sin embargo, en los últimos años estamos asistiendo a un aumento en el número de aislamientos de otras especies (con una mayor resistencia a antifúngicos). La infección por hongos del género Aspergillus constituye una de las principales causas de muerte en los pacientes con $\mathrm{TPH}^{6}$. La mayoría de estas infecciones están causadas por A. fumigatus, mientras que $A$. flavus y $A$. niger son especies menos frecuentes. La aspergilosis suele afectar inicialmente a los senos paranasales y al pulmón (la presentación clínica más frecuente es la aspergilosis pulmonar invasiva con fiebre, dolor torácico y expectoración hemoptoica), pero en estadios avanzados puede diseminarse a cualquier órgano. La infección por Cryptococcus neoformas es poco frecuente, pero es obligado descartarla en los pacientes con meningitis linfocitaria. La neumonía por $P$. jiroveci suele observarse en el período intermedio post-trasplante, y cursa habitualmente con afección pulmonar difusa acompañada de fiebre, tos no productiva e hipoxemia ${ }^{7}$.

\section{Infecciones virales}

La infección viral en este tipo de pacientes sigue un patrón secuencial según la fase de recuperación del status inmunológico. Esto es especialmente evidente en la reactivación de los herpesvirus. El desarrollo de estrategias eficaces de profilaxis y tratamiento anticipado han hecho surgir nuevos problemas como la aparición de infecciones tardías por Citomegalovirus (CMV) o las presentaciones clínicas inhabituales ${ }^{8}$. Del mismo modo ha aumentado la incidencia de enfermedades linfoproliferativas como por ejemplo las asociadas al virus de Epstein-Barr (VEB).

La infección más frecuente durante el período post-trasplante es la causada por el virus Herpes simple (VHS). Habitualmente es el resultado de la reactivación de una infección latente (hasta el $80 \%$ de los pacientes seropositivos desarrollarán una enfermedad clínica dentro de las primeras 4 semanas post-TPH). Se recomienda la determinación del estado inmune frente al VHS en todos los receptores de TPH, pero no es preciso realizarla en el donante ya que no se ha documentado la transmisión del VHS a través de hemoderivados. La manifestación más frecuente es la gingivoestomatitis por VHS-1; ésta puede progresar a esofagitis, traqueobronquitis y neumonía (entidad rara pero asociada a una gran mortalidad), además de constituir un factor de riesgo para el desarrollo de infecciones bacterianas y/o fúngicas ${ }^{9}$. La hepatitis herpética es otra entidad rara que cuando aparece acarrea una gran mortalidad. La encefalitis es extremadamente rara en este grupo de pacientes. La infección por el VHS-2 es poco frecuente y habitualmente está asociada a úlceras genitales.

La infección por el virus Varicela zóster (VVZ) ocurre hasta en el 50\% de los receptores de TPH (habitualmente se trata de una reactivación). Más del $85 \%$ de los casos ocurren dentro del primer año, situándose la mediana en el quinto mes ${ }^{10}$. La presentación clínica y sus complicaciones son similares a las de otros pacientes inmunodeprimidos. Se puede presentar como varicela, herpes zóster monometamérico (forma más frecuente), herpes zóster generalizado y enfermedad diseminada con afectación visceral. Los pacientes que adquieren la infección primaria durante el primer año tienen mayor riesgo de sufrir una varicela diseminada. Otras complicaciones incluyen el desarrollo de coagulación intravascular diseminada y sobreinfección bacteriana.

La infección por CMV aparece hasta en el $80 \%$ de los receptores de TPH. El período de máximo riesgo comprende desde el día 30 hasta los 80-120 días post-TPH, similar a lo observado en el trasplante de órgano sólido (TOS). Con las estrategias de prevención utilizadas en la actualidad, la incidencia de enfermedad se ha reducido desde un 20-30\% al inicio de los años 90 a un 5-10\% en la actualidad. La infección por CMV puede ser de carácter exógeno, como ocurre en el caso de receptores seronegativos que reciben médula u otros hemoderivados de receptores seropositivos, o ser consecuencia de reactivación de una infección latente. Los pacientes seropositivos tienen un $75 \%$ de riesgo de sufrir una reactivación y, si no se toman medidas preventivas, un 20-30\% de probabilidades de desarrollar enfermedad. La detección de CMV en cultivo de orina o faringe no se correlaciona con la 
existencia de enfermedad, sin embargo, la viremia y la detección en el lavado bronquioalveolar de pacientes asintomáticos, sí tiene valor predictivo de desarrollo posterior de enfermedad invasiva. El espectro clínico de la enfermedad por CMV en receptores de TPH es muy amplio, abarcando desde la infección asintomática hasta la neumonía intersticial, potencialmente fatal (proceso pulmonar agresivo con patrón radiológico intersticial y evidencia concomitante de infección por CMV en ausencia de otra etiología $)^{11}$. Otros síndromes clínicos son la enfermedad gastrointestinal (esofagitis, gastroenteritis, colitis y hepatitis). La afectación del SNC (encefalitis y retinitis) es rara en comparación con lo que ocurre en otros pacientes inmunodeprimidos.

El VEB permanece latente en las células de las glándulas salivares y en los linfocitos B del 90\% de los adultos sanos. La reactivación del VEB en pacientes sometidos a TPH puede dar lugar a una proliferación incontrolada de linfocitos B, siendo éste el origen de los síndromes linfoproliferativos asociados al VEB (SLP-VEB). La incidencia acumulada es del 1\% en 10 años, si bien la mayoría ocurren durante los primeros 6 meses $^{12}$. Los factores de riesgo para desarrollar un SLP-VEB son el tratamiento de inmunodeficiencias congénitas, la enfermedad de injerto contra huésped (EICH), el uso de gammaglobulina antitimocítica (OKT3), el grado de disparidad HLA entre receptor y donante y la deplección de células T del paciente sometido a TPH. De las tres formas de SLP-VEB descritas (hiperplasia polimorfa y policlonal de células $\mathrm{B}$, linfoma polimórfico de células $\mathrm{B}$ poli u oligoclonal que se presenta como mononucleosis agresiva, y linfomas no Hodgkin monomorfos monoclonales) los SLP-VEB observados en receptores de TPH son casi exclusivamentes linfomas B monomórficos que derivan de las células del donante ${ }^{13}$. La clínica se caracteriza por fiebre (80\%), adenopatías (50\%), amigdalitis (33\%) y afectación hepática o gastrointestinal (33\%), pulmonar (25\%), nasofaríngea (12\%) o del SNC (11\%). El diagnóstico requiere la demostración del VEB en los linfocitos proliferantes mediante inmunohistoquímica, anticuerpos monoclonales anti-EBNA, técnicas de PCR o hibridación in situ.
La infección activa por el herpesvirus tipo 6 (VHH-6) en estos pacientes se ha asociado a diferentes complicaciones (exantema, EICH, neumonitis, sinusitis, encefalitis, episodios febriles y retraso o supresión del injerto medular), aunque el cuadro clínico que predomina es la reactivación asintomática ${ }^{14}$. Alrededor del 30$45 \%$ de los pacientes desarrollan una viremia durante las primeras 2-4 semanas post-trasplante. Es más frecuente en el trasplante alogénico que en el autólogo. El VHH-6 parece tener un gran neurotropismo, y algunos autores sostienen que podría ser la causa principal de meningoencefalitis en el trasplante alogénico.

El impacto de la infección por el virus de la Hepatitis B (VHB) en la población de pacientes sometidos a TPH no está bien establecido. En pacientes con antígeno Australia positivo se recomienda la determinación del antígeno $\mathrm{HBe}$, de anticuerpos anti-HBe y del ADN viral (se debe tener en cuenta la alteración del sistema inmune en estos pacientes a la hora de interpretar los resultados serológicos). $\mathrm{La}$ infección por el VHB puede proceder del donante, del receptor o de la hemoterapia post-TPH. Las consecuencias clínicas de la infección por este virus en pacientes sometidos a TPH suelen ocurrir de manera precoz. Cuando se disminuye la inmunosupresión (alrededor del cuarto mes) puede producirse un brote de hepatitis como consecuencia de la reactivación (5$54 \%$ ); esto puede dar lugar a una hepatitis fulminante en alrededor de un $10 \%$ de los pacientes (la mutante precore tiene una mayor riesgo de causar una hepatitis fulminante) $)^{15}$.

La infección por el virus de la Hepatitis $\mathrm{C}$ (VHC) se transmite habitualmente desde un donante virémico a un receptor de TPH. Las hepatitis por VHC post-TPH aparecen en un $30 \%$ de los casos siendo en general un cuadro benigno y autolimitado (la hepatitis fulminante es rara). El cuadro de hepatitis aparece habitualmente entre el día 60 y 120 post-TPH (coincidiendo con el descenso de la inmunosupresión y la recuperación inmune $)^{16}$. La evolución a hepatitis crónica varía según las series (5-70\%) siendo la progresión a cirrosis la consecuencia más grave de la infección. 
La infección por virus respiratorios puede aparecer en cualquier momento tras el trasplante dependiendo del riesgo de exposición del paciente. Los virus que más frecuentemente se ven implicados son el virus respiratorio sincitial (VRS), el virus de la gripe, los parainfluenzavirus, los picornavirus, los adenovirus (capaces de mantenerse en forma latente) y los metapneumovirus. Estos virus han cobrado un papel predominante en la etiología de la infección nosocomial debido a la disminución de infección por CMV (por el desarrollo de estrategias eficaces de prevención). El estado de portador asintomático en estos pacientes es excepcional, estando estos virus implicados en aproximadamente en un $30 \%$ de los pacientes con sintomatología respiratoria ${ }^{17}$. El VRS es el más frecuente en la mayoría de las series (30-50\%). En el 40\% de los casos la enfermedad permanece limitada al tracto respiratorio superior, sin embargo, hasta un $60 \%$ de los pacientes desarrollarán una neumonía (ya sea viral primaria o bacteriana secundaria). La mortalidad asociada al desarrollo de neumonía es elevada (40$60 \%)$.

La infección crónica o persistente por parvovirus B19 se ha descrito como causa de anemia aplásica en receptores de $\mathrm{TPH}^{18}$. Los poliomavirus BK y JC, tras la infección primaria, quedan latentes y pueden reactivarse como consecuencia de la inmunosupresión ${ }^{19}$. De hecho, se ha demostrado una reactivación del virus $\mathrm{BK}$ en el $55 \%$ de los pacientes sometidos a TPH (cistitis hemorrágica tardía). Sin embargo, muchos pacientes excretan BK en orina sin signos de cistitis hemorrágica. Además, se han descrito algunos casos de leucoencefalopatía multifocal progresiva en relación con reactivaciones del virus JC.

\section{INFECCIONES EN EL TRASPLANTE DE ÓRGANO SÓLIDO}

La mayoría de las infecciones ocurren en los primeros meses post-trasplante. Los tipos de infección observados en este período no son uniformes pero siguen un esquema temporal típico ${ }^{20}$. Durante el primer mes las infecciones habituales son las que podrían observarse después de cual- quier procedimiento quirúrgico: neumonía, infección del sitio quirúrgico, infección del tracto urinario e infección asociada a catéter intravascular. Excepto las posibles reactivaciones del VHS, no suelen observarse infecciones relacionadas con una deficiencia de las células T. Pasado un mes, las infecciones relacionadas con el procedimiento quirúrgico son menos frecuentes y comienzan a aparecer las infecciones oportunistas relacionadas con la disfunción de estas células ${ }^{21}$. Este esquema puede tener ligeras variaciones dependiendo del tipo de trasplante; por ejemplo, en los receptores de trasplante hepático $(\mathrm{TH})$, la infección post-quirúrgica puede aparecer durante el segundo o tercer mes debido a posibles reintervenciones $o$ retrasplantes. En el caso de los receptores de TH o pulmonar (TP) pueden aparecer infecciones fúngicas oportunistas durante el primer mes debido a su elevada susceptibilidad. Seis meses tras el trasplante, las infecciones que ocurren son, en general, las habituales que ocurren en la población normal, si bien es verdad que tras este período pueden aparecer reactivaciones de infecciones virales o infecciones virales crónicas. Algunas infecciones pueden ocurrir de forma tardía tras el trasplante, como por ejemplo la hepatitis subaguda o crónica, especialmente la ocasionada por el VHC, las verrugas vulgares o los SLP$\mathrm{VEB}^{22}$. Otro tipo de infecciones, como las reactivaciones del VVZ pueden ocurrir en cualquier momento tras el trasplante. Los receptores de TP con rechazo crónico, pueden desarrollar una bronquiolitis obliterante aumentando así su susceptibilidad a sufrir neumonías bacterianas recurrentes $^{23}$.

\section{Infecciones bacterianas}

Las infecciones bacterianas son las más frecuentes en los receptores de TOS y también las que ocasionan una mayor mortalidad. La incidencia varía según el tipo de trasplante (hepático: 33-68\%, pulmonar: $54 \%$, renal: $47 \%$, pancreático: $35 \%$, cardíaco: 21-30\%). La transmisión de bacterias a través del injerto es muy frecuente en el TP, el cual presenta una colonización bronquial del injerto hasta en el $50 \%$ de los casos. Sin embargo es muy raro en el resto de TOS, en 
los que el órgano trasplantado es habitualmente estéril. Los restantes mecanismos patogénicos no difieren de los de la población no trasplantada. El diagnóstico es difícil en la mayoría de las ocasiones debido al amplio abanico de posibles patógenos y a la atenuación de las manifestaciones clínicas debido a la inmunosupresión.

\section{Receptores de trasplante renal (TR)}

Las bacterias constituyen la primera causa en frecuencia de infección durante el primer mes post-trasplante, y la segunda (tras los virus) a partir del segundo mes. La infección del tracto urinario es la más frecuente, de hecho, la mayor parte de las bacteriemias en estos pacientes tienen su origen en el tracto urogenital ${ }^{24}$. La etiología es similar a la observada en pacientes no trasplantados (Escherichia coli, otras enterobacterias, Pseudomonas aeruginosa, entero$\operatorname{cocos}$ y especies de levaduras). Otros patógenos menos habituales son por ejemplo Mycoplasma hominis y Ureaplasma urealyticum. En aquellos pacientes con infecciones recidivantes deben buscarse factores subyacentes como reflujo ureteral, estenosis ureterovesical o vejiga neurógena. La neumonía bacteriana era una complicación menos frecuente en los receptores de trasplante renal que la producida por oportunistas como los hongos filamentosos, CMV o $P$. jiroveci, sin embargo hoy en día, y debido al mejor control de estas infecciones oportunistas, ha aumentado la incidencia de las neumonías bacterianas ${ }^{25}$. Las infecciones de la herida quirúrgica son relativamente infrecuentes, pero cuando ocurren representan un problema grave, sobre todo si afectan al espacio perinéfrico.

\section{Receptores de trasplante cardíaco (TC)}

Los receptores de TC tienen más infecciones y éstas son más graves que las que presentan los receptores de TR. Las infecciones bacterianas más frecuentes son la neumonía bacteriana (sobre todo en el período post-trasplante inmediato), la bacteriemia y las infecciones de piel y partes blandas. La mediastinitis es una complicación propia de este tipo de pacientes ${ }^{26}$. Los patógenos observados son similares a los encontrados en otros pacientes sometidos a cirugía cardiotorácica ( $S$. aureus y ECN). Cuando el diagnóstico clínico de infección es claro y los cultivos son negativos, debe pensarse en otros patógenos como $\mathrm{Myco}$ plasma hominis, Legionella spp. o Nocardia $\mathrm{spp}^{27}$. A pesar de los traumatismos debidos a las biopsias endomiocárdicas, estos pacientes no presentan un riesgo más elevado de endocarditis.

\section{Receptores de trasplante de corazón-pulmón y pulmón}

Los receptores de corazón-pulmón tienen complicaciones infecciosas similares a las de los receptores de corazón, aunque éstas suelen ser más graves (estas infecciones ocasionan más el $75 \%$ de las muertes en el caso de los trasplantados de corazón-pulmón y casi el 50\% de las del TP). En el $65 \%$ de los TP se produce una bronquiolitis obliterante durante el período posttrasplante tardío. Esta complicación se asocia con infecciones pulmonares recidivantes $^{28}$. Un aspecto a remarcar en el TP único es la posible aparición de infecciones en el pulmón nativo no trasplantado. Los donantes potenciales por lo general están intubados en Unidades de Cuidados Intensivos antes de que sus órganos sean extraídos. Las vías aéreas de estos donantes se encuentran con frecuencia colonizadas por diferentes microorganismos y puede, incluso, haber alguna infección oculta. Es útil, por tanto, obtener cultivos de secreciones respiratorias del donante para poder definir así un correcto tratamiento antibiótico profiláctico o precoz.

\section{Receptores de TH}

El TH se diferencia de otras cirugías de trasplante en su duración, su dificultad técnica y en la frecuencia de complicaciones hemorrágicas. Además, muchos receptores de TH están malnutridos y presentan alteraciones metabólicas graves de forma basal. Los receptores de TH tiene unas tasas de infección más elevadas que los que reciben TR o TC, estando la mayoría de las muertes relacionadas con problemas infecciosos. Alrededor del 50\% de estas infecciones ocurren durante las dos primeras semanas posttrasplante. Las infecciones graves que ocu- 
rren en estos pacientes son infecciones bacterianas o fúngicas que tienen su origen habitualmente en el tracto gastrointestinal ${ }^{29}$. Las bacterias son los patógenos que están implicados con mayor frecuencia (la incidencia oscila según estudios entre un 35 y un 70\%). Las infecciones más frecuentes son las intraabdominales (abscesos, peritonitis), las de la vía biliar (la estenosis biliar y los estudios radiológicos sobre la vía biliar predisponen a la existencia de una colangitis), de la herida quirúrgica, neumonías y bacteriemias. La mayoría de los abscesos en el hígado trasplantado se relacionan con problemas quirúrgicos y se manifiestan habitualmente como una enfermedad febril con bacteriemia y leucocitosis. Suele estar implicada una microbiota polimicrobiana (enterobacterias, enterococos y microorganismos anaerobios, aunque no es infrecuente la participación de estafilococos y de levaduras). Los abscesos intraabdominales son más frecuentes en aquellos pacientes sometidos a intervenciones largas y/o complejas. Sólo una tercera parte de estos abscesos cursan con bacteriemia. Suelen ser perihepáticos, pero también pueden ser esplénicos y pericolónicos. En la mayoría de los casos hay fiebre, pero en algunos casos, como por ejemplo en los abscesos en los que está implicado Candida spp. puede no aparecer fiebre elevada. La peritonitis puede complicar a cualquier infección intraabdominal.

\section{Receptores de trasplante de páncreas}

El principal problema asociado del trasplante de páncreas es cómo se realiza el drenaje adecuado y seguro de las secreciones exocrinas. Estas secreciones se suelen drenar hacia la vejiga utilizando un segmento de duodeno, sin embargo, las complicaciones infecciosas siguen siendo un problema a tener en cuenta en la actualidad ${ }^{30}$.

\section{Receptores de trasplante de intestino delgado}

El trasplante de intestino delgado se encuentra en las primeras etapas de su desarrollo clínico. Más del $90 \%$ de estos pacientes desarrollan infecciones importantes ${ }^{31}$. Predominan las infecciones piógenas intraabdominales y las bacteriemias.

\section{Otras infecciones bacterianas}

\section{Infección por especies de Nocardia}

Existen al menos cuatro especies de Nocardia patógenas para el hombre; $N$. asteroides, $N$. farcinica, $N$. caviae y $N$. brasiliensis. La especie implicada con mayor frecuencia es $N$. asteroides, y la especie que muestra una mayor resistencia antibiótica es $N$. farcinica. Nocardia spp. es un bacilo grampositivo ramificado ubicuo, siendo las vías de adquisición más frecuentes la inhalación y la inoculación directa. Nocardia spp. puede formar parte de la microbiota respiratoria normal, por lo que el aislamiento de este microorganismo a partir de una muestra respiratoria no indica necesariamente enfermedad. La tasa de infecciones por microorganismos del género Nocardia es mayor en los pacientes TC que en los receptores de riñón o hígado ${ }^{32}$. Aunque el órgano que se afecta inicialmente en la mayoría de los casos es el pulmón, la nocardiosis en este tipo de pacientes debe siempre considerarse una enfermedad diseminada o sistémica (cerebro, hueso, piel, ojos, pericardio,...)

\section{Infecciones por Rhodococcus equi}

$R$. equi es un patógeno oportunista que fue descrito inicialmente ligado al SIDA, pero que puede afectar también a pacientes sometidos a $\mathrm{TOS}^{33}$. Es un cocobacilo grampositivo que puede formar filamentos. La infección se adquiere habitualmente por inhalación, siendo frecuente encontrar un antecedente de exposición a animales (especialmente caballos). Inicialmente afecta al pulmón (fiebre, tos seca y dolor torácico de evolución tórpida), pudiendo diseminarse a distancia. Se debería sospechar una infección pulmonar por este microorganismo en pacientes trasplantados con un nódulo pulmonar cavitado y en el que se haya descartado la presencia de Nocardia spp., M. tuberculosis y Aspergillus spp.

\section{Infección vírica}

Las infecciones víricas en los pacientes sometidos a TOS pueden tener una doble consecuencia; los efectos de la propia enfermedad infecciosa, y el efecto inmuno- 
modulador que contribuye a su vez al rechazo del injerto y a una mayor predisposición a sufrir otras infecciones o neoplasias. No todos los pacientes trasplantados tienen la misma susceptibilidad a las infecciones oportunistas virales. La ausencia de protección inmunológica específica frente a determinados virus antes del trasplante (pacientes seronegativos) es un factor de riesgo para contraer la primoinfección después del trasplante, y además para que ésta sea más grave. Sin embargo, la mayoría de infecciones en pacientes adultos resultan de la reactivación de virus latentes. La utilización de determinados fármacos inmunosupresores como, por ejemplo, anticuerpos antilinfocitarios, facilita la posibilidad de desarrollar estas infecciones virales oportunistas. Los virus del grupo herpes son los que producen con mayor frecuencia infección en los receptores de TOS. Sin embargo, también debemos tener en cuenta otros virus, denominados emergentes. Entre ellos haremos referencia a los virus de las hepatitis, VIH, parvovirus B19, poliomavirus y herpes virus 6,7 y 8 . Además, no debemos olvidar la especial susceptibilidad que presentan este tipo de pacientes a los adenovirus, VRS o virus de la influenza.

\section{Infección por $C M V$}

La infección por CMV es la infección vírica más frecuente en el paciente sometido a TOS. De forma global, hasta el $60-90 \%$ de los receptores de TOS sufren alguna infección por CMV tras el trasplante ${ }^{34}$. Sin embargo, el aislamiento de CMV en una muestra clínica (incluida la sangre) no siempre es sinónimo de enfermedad por este virus, y por lo tanto, no siempre es necesario instaurar un tratamiento específico. La enfermedad por CMV en el paciente sometido a TOS aparece habitualmente entre el segundo y tercer mes post-trasplante. Las manifestaciones clínicas son variadas, pudiendo causar desde un síndrome febril con o sin leucotrombocitopenia y sin evidencia de afección visceral, hasta una enfermedad diseminada (la retinitis es excepcional, al contrario de lo que ocurre en los pacientes VIH positivos) ${ }^{35}$. La neumonitis es menos frecuente que en los receptores de TPH. La adquisición de la infección por CMV a través del órgano trasplantado (receptor seronegativo frente a CMV que recibe un órgano procedente de un donante seropositivo) o de los productos sanguíneos utilizados durante la cirugía, coloca al receptor en un alto riesgo de desarrollar una enfermedad por $\mathrm{CMV}^{36}$. El intestino trasplantado, al igual que el hígado y el pulmón parecen ser especialmente susceptibles a la infección por CMV. A partir del sexto mes post-trasplante la infección por CMV es muy infrecuente, siendo la corioretinitis la principal forma de presentación.

\section{Infección por VHS}

Las infecciones causadas por VHS en adultos son, en general, el resultado de una reactivación de un virus latente. La infección suele aparecer durante las primeras 3-4 semanas post-trasplante y suele ser de características leves. La manifestación clínica más común es el herpes labial en la segunda semana post-trasplante. Sin embargo, algunos pacientes pueden complicarse con lesiones ulcerativas graves en superficies cutáneo-mucosas o manifestaciones viscerales (neumonitis, hepatitis,...) Las lesiones son más severas y duraderas que las que ocurren en el paciente inmunocompetente, y pueden asociarse a lesiones intraorales o esofágicas (la esofagitis por VHS es indistinguible clínicamente de la producida por CMV o levaduras $)^{37}$.

\section{Infección por $V V Z$}

La infección por el VVZ causa dos entidades clínicas distintas dependiendo de que se trate de una primoinfección (varicela) o una reactivación (herpes zóster). La mayor parte de pacientes adultos trasplantados son seropositivos frente al VVZ, por lo que no estarían en riesgo de desarrollar varicela. La primoinfección puede ocurrir en cualquier momento tras el TOS, no existiendo evidencia hasta el momento de que este virus se transmita a través del órgano trasplantado. La varicela puede cursar como una infección diseminada con neumonía hemorrágica, encefalitis, pancreatitis, hepatitis,... En estos casos el pulmón es el principal órgano diana, desarrollando estos pacientes una neumonía 3-7 días des- 
pués del inicio de las lesiones cutáneas. La incidencia de herpes zóster en pacientes receptores de un trasplante oscila entre un 5 y un $13 \%$, y suele ocurrir a partir del sexto mes post-trasplante. El herpes zóster en la población trasplantada no se diferencia del que se observa en el resto de la población, sin embargo puede existir afectación de más de un dermatomo.

\section{Infección por virus herpes tipo 6 (VHH-6)}

Este virus es el agente causal del exantema súbito de la infancia. La importancia real de la infección por el VHH-6 en los pacientes trasplantados no se conoce con exactitud. Según algunas series, la incidencia de infección post-trasplante varía entre un 23 y un $66 \%$. Se ha descrito en TP, TR, TH y reno-pancreático. La infección por este virus se ha asociado con cuadros febriles en las primeras semanas post-trasplante, además de con casos graves de meningoencefalitis, neumonitis, hepatitis y aplasia medular ${ }^{38}$. Además, puede actuar como cofactor del CMV y tiene un cierto efecto sobre los linfocitos T lo cual podría favorecer el rechazo del órgano trasplantado o la aparición de infecciones oportunistas por hongos o bacterias.

\section{Infección por virus herpes tipo 7 (VHH-7)}

Al igual que el VHH-6, se encuentra ampliamente diseminado en la población general, elevándose la seroprevalencia (60$80 \%$ ) en torno a los dos años de edad. Su principal lugar de replicación son las glándulas salivares (transmitiéndose de hecho a través de la saliva). Puede causar un cuadro clínico similar al que produce el VHH-6 o un cuadro similar a la mononucleosis. Varios autores han observado que la infección por el VHH-7 se asocia con una mayor incidencia de enfermedad por CMV y con un aumento del rechazo del injerto.

\section{Infección por el virus herpes tipo 8 (VHH-8) (virus herpes asociado al sarcoma de Kaposi)}

Fue denominado inicialmente como virus herpes asociado a sarcoma de Kaposi (SK) debido a que inicialmente se detec- tó en pacientes con SIDA que presentaban este tipo de neoplasia. Esta neoplasia es relativamente común entre los pacientes trasplantados, presentándose en la mayoría de las ocasiones como formas viscera$\mathrm{les}^{39}$. En Francia se ha observado una prevalencia de un $8 \%$ en los donantes y también de un $8 \%$ en los receptores. La infección por el VHH-8 puede ser tanto previa al trasplante como transmitida por el donante. En una revisión de 28 casos de SK en pacientes trasplantados renales, 23 casos (82\%) se debieron a una reactivación del virus y 5 (18\%) a una primoinfección. En la actualidad, y dada la agresividad del SK, se debate la necesidad de realizar un cribado serológico frente al VHH-8 en pacientes trasplantados según la seroprevalencia de cada país con el objetivo de poder administrar antivirales de forma profiláctica.

\section{Infección por el $\mathrm{VEB}$}

La infección por este virus en el paciente trasplantado puede producir una mononucleosis infecciosa similar a la del paciente inmunocompetente. La infección puede también asociarse con el desarrollo de un SLP-VEB. La incidencia de SLP-VEB oscila entre 1-14\% siendo mayor en población pediátrica y en los pacientes sometidos a trasplante de intestino, pulmón y de páncreas-riñón ${ }^{40}$. El espectro clínico de esta entidad es bastante amplio, siendo muchas veces multifocal, con afección visceral y con frecuente afección del órgano trasplantado. La seronegatividad del receptor frente al VEB antes del trasplante, la utilización de OKT3 para el tratamiento del rechazo, el tratamiento con tacrolimus y el desarrollo de enfermedad por CMV son factores de riesgo para el desarrollo de un SLP-VEB.

\section{Infección por papovavirus}

Son virus DNA que están divididos en dos géneros, polyomavirus y papilomavirus. Estos virus tienen además potencial oncogénico.

\section{Polyomavirus: virus BK y JC}

Se han descrito casos de cistitis hemorrágica y estenosis ureteral por $\mathrm{BK}$ en 
pacientes trasplantados, así como, y de forma excepcional, casos de leucoencefalopatía multifocal progresiva por el virus $\mathrm{JC}$ en pacientes sometidos a $\mathrm{TR}^{41}$.

\section{Papilomavirus}

Los receptores de TOS tienen un elevado riesgo de desarrollar infección anogenital por papilomavirus, además tienen una incidencia mayor que la población inmunocompetente de neoplasis de cérvix asociados a dichos virus.

\section{Infección por parvovirus B19}

Las manifestaciones clínicas que produce en pacientes trasplantados se encuentran en relación habitualmente con alteraciones hematológicas. La infección grave por este virus es rara en el paciente trasplantado, sin embargo hay casos descritos de neumonía, aplasia medular y hepatitis grave en pacientes sometidos a TH y TC.

\section{Infección por el virus de la Inmunodeficiencia Humana (VIH)}

La infección por el VIH se considera, por lo general, una contraindicación para recibir un TOS. En los casos en los que se ha realizado un TOS a un paciente VIH positivo (debido por ejemplo a que la infección VIH no era conocida de forma previa al trasplante) la evolución de la función del injerto ha sido similar a la de los pacientes no infectados. Sin embargo, la utilización de inmunosupresores para impedir el rechazo parece acelerar la progresión de la infección. A la vista de los buenos resultados respecto al control de la infección VIH con las nuevas pautas de tratamientos antiretrovirales de gran actividad, algunos grupos se están planteando la posibilidad de ofrecer el trasplante de órgano sólido a determinados pacientes ${ }^{42}$.

\section{Infección por $\mathrm{VHB}$}

Los pacientes infectados por virus de hepatitis representan el mayor grupo entre todas las indicaciones de TH. Además, la recidiva de la enfermedad sobre el injerto es elevada. Esto se debe a la permanencia de los virus en órganos o tejidos distintos del hígado explantado. La infección del injerto en pacientes sin profilaxis llega a ser del 50-100\%. La infección del injerto conlleva una evolución más rápida de la hepatopatía que en los pacientes no inmunodeprimidos. La importancia de la infección por el VHB en el paciente portador de un TR es cada vez menor debido a las estrategias adecuadas de vacunación, así como de las medidas preventivas. El riesgo de transmisión de la infección a través de los órganos de donantes con infección aguda o crónica es elevado, y las infecciones que se adquieren por esta ruta tienen mal pronóstico. La causa más importante de enfermedad hepática en el TR son los virus $\mathrm{B} \mathrm{y} \mathrm{C}^{43}$. La incidencia actual de adquisición peritrasplante del VHB es muy baja $(0,002 \%)$, siendo la enfermedad hepática progresiva en este grupo del $7 \%$. La primoinfección en el postrasplante reciente, coincidiendo con la fase de mayor inmunosupresión, es más grave, tiene mayor riesgo de hepatitis fulminante y mayor mortalidad (60\%). Los efectos clínicos de la infección por el VHB ocurren habitualmente en dos etapas: durante los dos primeros años post-trasplante contribuye a la inmunosupresión y a partir de los dos años, el paciente evoluciona de manera inexorable hacia la enfermedad crónica, el hepatocarcinoma o ambos ${ }^{44}$.

\section{Infección por $\mathrm{VHC}$}

La cirrosis hepática en relación con el VHC es la indicación más frecuente de TH en muchos centros. La persistencia de la infección tras el trasplante aparece prácticamente en todos los enfermos, aunque el porcentaje de pacientes con hepatitis sobre el injerto varía según publicaciones $^{45}$. La infección por el VHC se caracteriza por su cronicidad. La infección generalmente tiene un curso subclínico y un porcentaje elevado de pacientes puede desarrollar hepatitis crónica, cirrosis y hepatocarcinoma. El VHC es la causa más frecuente de enfermedad hepática progresiva en los pacientes portadores de TR (si bien es verdad que muchos receptores están ya infectados por el virus antes del trasplante). La historia natural de la infección por el VHC en el TOS es poco conocida. Se ha demostrado una disminución de la supervivencia de estos pacientes en la 
segunda década del trasplante debido, por una parte, al desarrollo de cirrosis descompensada y por otro al aumento de sepsis por gramnegativos ${ }^{46}$. El VHC también puede producir daños en el injerto a través de mecanismos inmunológicos.

\section{Infección por VRS}

Puede originar tos, fiebre, rinorrea, sinusitis y neumonía en pacientes trasplantados, pudiéndoles llevar incluso a la muerte $^{47}$. Algunos autores han sugerido una posible asociación entre esta infección y el rechazo en el caso del trasplante renal.

\section{Infección por virus Parainfluenza}

Produce afectación del tracto respiratorio con fiebre, tos, rinorrea, faringitis y, en algunos casos neumonías que pueden llegar a ser fatales.

\section{Infección por virus Influenza}

Además de la clínica habitual de un síndrome gripal, puede producir bronquitis y neumonía que en ocasiones se complica con neumonías bacterianas. La infección se asocia con una mayor tasa de rechazos.

\section{Infección por Adenovirus}

Pueden causar cuadros de infección del tracto respiratorio superior e inferior, conjuntivitis, nefritis túbulo-intersticial, cistitis hemorrágica y afectación hepática $\mathrm{y}$ gastrointestinal ${ }^{48}$.

\section{Infección por micobacterias \\ Infección por Mycobacterium tuberculosis}

La incidencia de tuberculosis (TBC) en nuestro medio entre los receptores de trasplante es unas veinte veces superior a la de la población general, siendo la mortalidad relacionada de aproximadamente un $20 \%{ }^{49}$. La TBC pulmonar es la principal forma de presentación, pero las formas extrapulmonares y diseminadas son relativamente frecuentes ${ }^{50}$. No parecen existir diferencias significativas en el riesgo de TBC en los receptores de hígado, corazón o riñón, aunque en este último la incidencia suele ser menor. La incidencia de TBC en otros tipos de trasplante como los de páncreas, pulmón o corazón-pulmón no se conoce con exactitud. Algunos autores han señalado que el uso de anticuerpos antilinfocitarios incrementa el riesgo de diseminación de una TBC. La mayoría de los pacientes desarrollan la TBC dentro de los primeros 9 meses post-trasplante, aunque hay casos descritos hasta 2-5 años después del trasplante ${ }^{51}$. Los síntomas más frecuentes son fiebre, tos, disnea, artromialgias, sudoración nocturna y pérdida de peso. Hasta una tercera parte puede tener una radiología de tórax normal, y muchos de ellos presentan una prueba de tuberculina negativa debido a anergia cutánea, lo cual dificulta el diagnóstico (de hecho, no es infrecuente que se retrase el diagnóstico durante semanas por falta de sospecha clínica). En esta población, la TBC condiciona una gran mortalidad que puede llegar hasta el 30\%.

\section{Infección por micobacterias atipicas}

Las micobacterias atípicas son microorganismos ubicuos capaces de colonizar o infectar a los pacientes trasplantados. En general, estos microorganismos tienen reservorios ambientales y animales, no estando bien documentada la transmisión de persona a persona. Se han descrito casos de infección por $M$. haemophilum (lesiones cutáneas) y $M$. chelonae en pacientes portadores de TR. M. marinum (lesiones cutáneas) se asocia típicamente con exposición a aguas de acuarios, piscinas o agua de mar. Otras especies que se han descrito incluyen: $M$. avium intracellulare (enfermedad pulmonar, digestiva o diseminada), $M$. fortuitum-chelonae (pulmón, piel, hueso, infección asociada a biomateriales), $M$. kansasii (infecciones pulmonares o diseminadas), $M$. ulcerans (formas cutáneas), M. abscessus, M. scrofulaceum, $M$. gastri, $M$. thermoresistibile, $M$. simiae, M. scrofulaceum, M. szulgai, M. xenopi y M. malmoense. Las infecciones por micobacterias atípicas han llegado a suponer hasta el $34 \%$ de algunas series de infecciones por micobacterias en el trasplante renal. Pueden causar lesiones nodulares cutáneas, osteoarticulares, pulmonares y digestivas de evolución tórpida, pero también pueden causar formas 
agudas y diseminadas con participación pulmonar importante. Estas infecciones suelen ocurrir en el post-trasplante tardío (dos años después del mismo) ${ }^{52}$. A menudo ocasionan síntomas crónicos que se manifiestan como lesiones cutáneas (nódulos cutáneos, abscesos, úlceras) en las extremidades, tenosinovitis e infecciones articulares (dedos, codos, rodillas y tobillos).

\section{Infección por hongos}

Las infecciones fúngicas son la tercera causa en frecuencia de infección en el paciente portador de TOS después de las infecciones bacterianas y víricas. La mortalidad de las formas invasoras en estos pacientes es superior al 50\% debido a la dificultad del diagnóstico precoz, la moderada eficacia de los tratamientos, las dificultades a la hora de utilizar ciertos antifúngicos por su toxicidad o interacciones con los inmunosupresores y la escasa experiencia en estrategias de prevención. La incidencia de la infección fúngica varía según el tipo de órgano trasplantado, siendo los receptores de un $\mathrm{TH}$ o TP los que tienen una mayor incidencia de este tipo de infecciones ${ }^{53}$. Los factores de riesgo para la infección fúngica invasora son el tratamiento con corticoides y antibióticos pretrasplante, la colonización previa con hongos, la situación clínica antes del trasplante, la cirugía complicada, la enfermedad por CMV, el exceso de inmunosupresión, el rechazo crónico y el retrasplante. Los hongos que están implicados con una mayor frecuencia en este tipo de infecciones son: Candida spp, Aspergillus spp., Cryptococcus neoformans, los hongos zigomicetos y Pneumocystis jiroveci. Candida spp. supone la etiología más frecuente para la mayoría de pacientes trasplantados, si hacemos excepción de los receptores de pulmón y corazón, en los que la infección fúngica está causada predominantemente por Aspergillus spp. Los trasplantados de corazón-pulmón tienen las tasas más altas de aspergilosis invasiva de entre todos los tipos de trasplante de órgano sólido. Las infecciones fúngicas son más frecuentes en los receptores de TH que en otros tipos de órganos. La incidencia osci- la entre un $20-40 \%$ con una tasa de mortalidad del 25 al $70 \%$. El 90\% de estas infecciones ocurren durante los primeros 2 meses post-trasplante ${ }^{54}$. Las infecciones por Aspergillus ocurren en el 1-5\% y son fatales en el $80-100 \%$ de los casos. El momento promedio de comienzo es un poco después del observado en las infecciones por Candida spp. Candida albicans es la especie más frecuentemente aislada. La mayoría de las infecciones aparecen durante los dos primeros meses después del trasplante ${ }^{55}$. Puede ocasionar enfermedad no invasiva o invasiva. Las infecciones invasivas pueden cursar como sepsis asociada al uso de catéteres, abscesos intraabdominales (hígado), infecciones del tracto urinario (riñón) y mediastinitis (pulmón y corazón).

\section{Infecciones por parásitos}

Las infecciones parasitarias en los pacientes trasplantados se relacionan con determinados factores de riesgo epidemiológicos como la visita o procedencia de determinadas áreas geográficas. Pueden aparaecer como resultado de la reactivación de infecciones latentes transmitidas por el injerto o como primoinfecciones. El número de los casos publicados en los últimos años ha ido en aumento. Este hecho puede deberse a factores como el aumento de trasplantes realizados en países donde estas enfermedades son endémicas, el aumento de viajes a estas zonas o el aumento en los movimientos migratorios de las poblaciones.

\section{Toxoplasmosis}

La importancia de la toxoplasmosis en los receptores de TC se debe a la presencia de microorganismos enquistados en el corazón del donante $\mathrm{e}^{56}$. Los pacientes trasplantados con riesgo son aquellos seronegativos que reciben órganos seropositivos. La toxoplasmosis clínica, por lo general, ocurre varios meses después del trasplante y se manifiesta habitualmente como neumonitis necrosante, miocarditis o encefalitis.

\section{Quiste hidatídico}

La experiencia con $\mathrm{TH}$ en pacientes con enfermedad hepática terminal por 
hidatidosis es favorable. La transmisión accidental de una hidatidosis a través del trasplante de un hígado, riñón, pulmón o corazón afectados de forma inadvertida por la enfermedad es una posibilidad real $^{57}$. Los quistes de Equinococcus granulosus son capaces de permanecer viables y recurrir en pacientes sometidos a $\mathrm{TH}$, sin embargo, la hidatidosis no parece exacerbarse por la inmunosupresión.

\section{Leishmaniasis}

Existen tres formas de enfermedad clínica producida por Leishmania spp.; la leishmaniasis visceral o kala-azar producida por L. donovani, la leishmaniasis cutánea o botón de Oriente causada por L. tropica, y la leishmaniasis cutáneomucosa causada por un total de 8 especies de Leishmania. La infección por Leishmania spp. es muy rara en el paciente trasplantado y es propia de países como España donde la enfermedad es endémica $^{58}$. La vía más frecuente de adquisición es la reactivación del parásito en una persona previamente infectada. La mayor parte de pacientes desarrollan la infección durante los 3-13 años posttrasplante. El síntoma más habitual es fiebre junto con afectación del estado general. Además se pueden observar signos como hepatoesplenomegalia, adenopatías y pancitopenia. El paciente desarrolla generalmente una infección diseminada. La mortalidad oscila en torno al $40 \%$ (muy superior a la observada en los pacientes con SIDA).

\section{Tripanosomiasis. Enfermedad de Chagas}

La enfermedad de Chagas está causada por Trypanosoma cruzi y debe sospecharse en cualquier paciente trasplantado con fiebre que provenga o haya vivido en América del Sur. Este parásito infecta fundamentalmente células de la neuroglía, del sistema mononuclear fagocítico, del tejido cardíaco y del tracto gastrointestinal. La forma de presentación más frecuente es la forma aguda con fiebre, vómitos y diarrea. Sin embargo, en el paciente trasplantado tienen más importancia las formas subagudas (hepatoesplenomegalia, linfadenopa- tía generalizada, miocarditis o meningoencefalitis) y crónicas (insuficiencia cardíaca, megaesófago y megacolon). El riesgo de reactivación de la enfermedad parece ser mayor en los receptores seropositivos, particularmente en aquellos sometidos a trasplante cardíaco ${ }^{59}$. Los pacientes con miocardiopatía producida por $T$. cruzi sometidos a trasplante pueden presentar recidivas agudas de la enfermedad de Chagas con manifestaciones clínicas consistentes en fiebre, miocarditis y lesiones cutáneas.

\section{Malaria}

Aunque la malaria es la infección parasitaria más frecuente en el mundo, hay pocos casos descritos en pacientes sometidos a TOS. Sin embargo, es esperable un incremento progresivo de esta infección debido al aumento de viajes realizados por pacientes trasplantados a zonas endémicas. Las vías de transmisión, además de la picadura de mosquitos del género Anopheles, podrían ser las siguientes: transfusión de sangre contaminada, reactivación de la enfermedad como consecuencia de la inmunosupresión e infección transmitida por el propio órgano trasplantado ${ }^{60}$.

\section{Estrongiloidiasis}

Strongyloides stercoralis es un helminto que puede producir infecciones severas en el paciente trasplantado. En España, la infección por este gusano es poco prevalente, pero se debe sospechar en pacientes que han vivido en áreas endémicas ${ }^{61}$. La infestación por larvas de Strongyloides stercoralis en pacientes trasplantados reviste los mismos riesgos que en otro tipo de pacientes inmunocomprometidos, en los que una infección asintomática puede convertirse en una enfermedad diseminada o en un síndrome de hiperinfección. Aunque lo más frecuente es que se produzca durante los primeros meses post-trasplante, se han descrito casos que han ocurrido hasta 10-20 años después del mismo. Si existe riesgo de estar parasitado, antes del trasplante debe realizarse un despistaje activo de la infección que permita un tratamiento eficaz pre-trasplante. 


\section{PREVENCIÓN Y TRATAMIENTO}

\section{Trasplante de precursores hematopoyéticos}

\section{Citomegalovirus}

El CMV es el agente infeccioso más frecuente en todos los tipos de trasplante y es el responsable tanto de efectos directos, como la enfermedad por CMV, como de efectos indirectos, como el rechazo. Es importante distinguir entre infección y enfermedad por CMV. La infección únicamente implica la detección del virus y la enfermedad representaría la expresión sintomática de la infección.

Actualmente existen dos estrategias para prevenir la enfermedad por CMV en el paciente trasplantado. La primera es la profilaxis y consiste en la administración de antivirales a todos los pacientes trasplantados con riesgo de desarrollar una infección por CMV, en ausencia de sospecha clínica y datos microbiológicos de infección. La segunda estrategia es el tratamiento anticipado de la infección, que consiste en la administración de un agente antiviral cuando, en pacientes asintomáticos, se determina positividad de pruebas microbiológicas indicativas de infección por CMV.

La monitorización mediante antigenemia y/o ADNemia, como método de valoración de respuesta al tratamiento, debe realizarse con periodicidad semanal mientras dure el tratamiento. El descenso no es inmediato y es posible observar incluso aumentos de estas cifras tras la primera semana de tratamiento, sin que ello sea representativo de fracaso terapéutico. El objetivo del tratamiento es la negativización de la prueba utilizada. Una vez finalizado el tratamiento debe continuarse la monitorización establecida. La persistencia de una prueba positiva mas allá de la primera semana debe hacernos sospechar que no existe respuesta al tratamiento. Esta falta de respuesta puede ser debida a la aparición de mutaciones en el genoma del virus, lo que se denomina resistencia viral o a factores propios del huésped en cuyo caso se habla de resistencia clínica. En estos casos es aconsejable realizar pruebas de resistencia viral, tanto genotípica o fenotípica. Si ello no es posible puede indicarse el cambio de antivírico.

\section{Prevención de la infección por CMV (Tabla 1)}

La prevención en estos pacientes comienza antes del trasplante. Si bien la situación inmunológica no contraindica la realización de un TPH alogénico, cuando el receptor es seronegativo, el donante también debería ser seronegativo. En el caso de un receptor seropositivo, cuando se trata de un donante no relacionado y no deplecionado de células $\mathrm{T}$, el hecho de que sea asimismo seropositivo puede mejorar la supervivencia ${ }^{62}$. Respecto a la utilización

Tabla1. Recomendaciones en la prevención de la infección por CVM en el TPH.

\begin{tabular}{lll}
\hline Antiviral & Profilaxis * & Tratamiento anticipado * \\
\hline Aciclovir & $\begin{array}{l}\text { i.v. } 500 \mathrm{mg} / \mathrm{m} 2 / 8 \text { horas y tras tolerancia } \\
\text { V.o. } 800 \mathrm{mg} \text { x } 5 \text { veces/día } \\
\text { DÍAS: }-5 \mathrm{a}+30 \text { (ó hasta }+120)\end{array}$ & No indicado \\
\hline Valaciclovir & $1.000 \mathrm{mg} / 6$ horas & No indicado \\
& DÍAS: $-5 \mathrm{a}+30$ (ó hasta +120$)$ & \\
\hline Ganciclovir i.v. & $5 \mathrm{mg} / \mathrm{kg} / 12$ horas x 5 días y continuar con & Inducción: $5 \mathrm{mg} / \mathrm{kg} / 12 \mathrm{horas}$ \\
& $5 \mathrm{mg} / \mathrm{kg} /$ día hasta DÍA +100 post-TPH & Mantenimiento: $6 \mathrm{mg} / \mathrm{kg} / \mathrm{día}$ \\
\hline Foscarnet i.v. & Escasa experiencia & Inducción: $60 \mathrm{mg} / \mathrm{kg} / 12 \mathrm{horas}$ \\
& Mantenimiento: $90 \mathrm{mg} / \mathrm{kg} /$ día & \\
\hline Cidofovir i.v. & No hay experiencia & Inducción: $3 \mathrm{mg} / \mathrm{kg} / \mathrm{semana} \mathrm{x} 2 \mathrm{dosis}$ \\
& & Mantenimiento: $3-5 \mathrm{mg} / \mathrm{kg} / 2 \mathrm{semanas}$ \\
\hline Valganciclovir & No hay experiencia clínica & Inducción: $900 \mathrm{mg} / 12 \mathrm{horas}$ \\
& & Mantenimiento: $900 \mathrm{mg} / \mathrm{día}$ \\
\hline
\end{tabular}

*Dosis recomendadas para función renal normal (Clcr $>70 \mathrm{ml} / \mathrm{min})$ y recuento de neutrófilos $>1.000 / \mu l$. 
de productos sanguíneos y en el caso del TPH alogénico, el receptor seronegativo con donante seronegativo solamente debe recibir productos seronegativos o pobres en leucocitos. En receptor seronegativo con donante seropositivo o en caso de TPH autólogo seronegativo, la transfusión de productos seronegativos o deplecionados en leucocitos también podría ser beneficiosa. No se recomienda el empleo de inmunoglobulinas en la prevención de la infección ni de la enfermedad por CMV.

La profilaxis con ganciclovir intravenoso se inicia tras el prendimiento del injerto a dosis de $5 \mathrm{mg} / \mathrm{kg} / 12 \mathrm{~h}$ durante 5 días y posteriormente cada $24 \mathrm{~h}$ hasta el día $+100^{63-65}$. Sin embargo, esta pauta profiláctica, además de incrementar el riesgo de neutropenia, puede retrasar la reconstitución inmune y, en consecuencia, incrementar el riesgo de enfermedad tardía por $\mathrm{CMV}^{66}$.

Dado que no se recomienda la profilaxis con ganciclovir oral, se han evaluado otras pautas de profilaxis vía oral como aciclovir o valaciclovir ya que presentan un mejor perfil de seguridad que el ganciclovir intravenoso. En esta línea, altas dosis de aciclovir reducen el riesgo de infección por CMV y mejoran la supervivencia, si bien no produce un efecto sobre la incidencia de enfermedad por $\mathrm{CMV}^{67,68}$. La administración de valaciclovir a dosis de $2 \mathrm{~g} /$ día frente a aciclovir oral a dosis de 800 mg x 4 veces/día, es más efectivo reduciendo la incidencia de infección por $\mathrm{CMV}^{69}$. En un estudio randomizado ${ }^{70} \mathrm{se}$ demuestra que valaciclovir oral tiene una eficacia similar a ganciclovir intravenoso para la prevención tanto de la infección ( $12 \%$ vs $19 \%$ ) como de la enfermedad $(2,4 \%$ vs $1,2 \%)$ por CMV y una mejor tolerancia clínica. En su contra se ha visto que es el fármaco que más veces tiene que ser sustituido, bien sea por ganciclovir intravenoso o foscarnet, por aparición de probable o probada infección o enfermedad por CMV durante el tratamiento. A pesar de ello el valaciclovir se constituye como una alternativa real y efectiva al ganciclovir intravenoso como régimen profiláctico.

El tratamiento anticipado puede realizarse con ganciclovir intravenoso o con foscarnet ya que son equivalentes en cuanto a eficacia ${ }^{71}$. El utilizar uno u otro dependerá del perfil de seguridad y de los tratamientos que haya realizado profilácticamente el paciente. La combinación de ambos fármacos a mitad de dosis no mejora el control de la infección por CMV con respecto a dosis plena de ganciclovir intravenoso y en cambio se asocia con una mayor toxicidad, tanto por disfunción renal como por anomalías electrolíticas $^{72}$. Cidofovir puede considerarse como una opción terapéutica de segunda línea y la eficacia de valganciclovir necesita ser evaluada prospectivamente en estudios randomizados.

\section{Tratamiento de la enfermedad por CMV}

La aparición de enfermedad por CMV debe considerarse como un fracaso en la estrategia preventiva. Actualmente no existen estudios controlados que apoyen una determinada opción terapéutica. No obstante, el ganciclovir por vía intravenosa sigue siendo el tratamiento de elección. En la neumonitis, dada su elevada morbimortalidad se recomienda la combinación con gammaglobulinas inespecíficas a dosis de $500 \mathrm{mg} / \mathrm{kg} /$ día a días alternos, hasta un total de 7 a 10 dosis $^{73}$. La gammaglobulina hiperinmune no ha demostrado ser superior a la inespecífica y esta última tampoco se ha demostrado eficaz en otras localizaciones de enfermedad por CMV. La duración del tratamiento es variable entre 2 y 4 semanas para la inducción a dosis de $5 \mathrm{mg} / \mathrm{kg} / 12 \mathrm{~h}$, seguido de un tratamiento de mantenimiento de otras 4 semanas a dosis de $5 \mathrm{mg} / \mathrm{kg} / 24 \mathrm{~h}$. En pacientes con pancitopenia, debe plantearse el foscarnet intravenoso a dosis de $60 \mathrm{mg} / \mathrm{kg} / 8 \mathrm{~h}$ ó 90 $\mathrm{mg} / \mathrm{kg} / 12 \mathrm{~h}$. Como pauta alternativa se recomienda el cidofovir, a dosis de 3 a 5 $\mathrm{mg} / \mathrm{kg} / \mathrm{semana}$ junto con probenecid e hidratación ${ }^{74}$, o la combinación de ganciclovir y foscarnet, a dosis plena. No se recomienda la combinación de foscarnet y cidofovir debido a su elevado riesgo de nefrotoxicidad. Otras pautas con actividad frente a CMV incluyen el fomivirsen ${ }^{75}$ principalmente cuando existe resistencia a ganciclovir, foscarnet y cidofovir. 


\section{Trasplante de órgano sólido \\ Prevención de la infección por CMV (Tabla 2)}

La profilaxis antiviral es capaz de prevenir la enfermedad por CMV y la mortalidad global precoz en el paciente con TOS. La disminución de la mortalidad es debida a la disminución de mortalidad por enfermedad por $\mathrm{CMV}^{76}$.

El trasplante de un órgano de donante seropositivo a un receptor seronegativo representa el principal factor de riesgo de desarrollo de enfermedad por CMV ${ }^{77-81}$. Sin profilaxis, el $70-90 \%$ de los pacientes tendrán infección por CMV, de los cuales entre el 50-80\% desarrollarán enfermedad por CMV. La mortalidad global, en ausencia de profilaxis, es de aproximadamente un $15 \%$, principalmente en aquellos que desarrollan neumonitis como expresión clínica de enfermedad por CMV. La utilización de inmunosupresores antilinfocitarios (globulinas antilinfocíticas o antitimocíticas, o los anticuerpos monoclonales OKT3) constituye, junto con el estado serológico de donante seropositivo/receptor seronegativo, las situaciones de alto riesgo para infección por $\mathrm{CMV}^{82}$. Otros factores de riesgo son la utilización de dosis elevadas de corticoides, las cargas virales elevadas de CMV, la estimulación alogénica, la coinfección por otros virus herpes, y la inmunosupresión, principalmente la utilización de micofenolato mofetil ${ }^{83-85}$. Si bien la situación serológica del donante no es criterio de exclusión para la realización de un trasplante, en los receptores seronegativos de donantes seronegativos, es recomendable que los hemoderivados suministrados sean CMV seronegativos $\mathrm{o}$ filtrados ${ }^{82}$.

El valganciclovir es un profármaco del ganciclovir de administración oral. Está aprobada su indicación para la prevención del CMV en receptores seronegativos de un órgano seropositivo. Su biodisponibilidad oral es de aproximadamente un $70 \%$ y estudios de farmacocinética en el trasplante hepático han evaluado que, a dosis de 450 y $900 \mathrm{mg}$ produce unas concentraciones séricas de ganciclovir similares a las conseguidas con ganciclovir intravenoso a dosis de 2,5 y de $5 \mathrm{mg} / \mathrm{kg}$, respectivamen- te ${ }^{86}$. Los resultados en Fase III del estudio internacional PV16000 concluyen que valganciclovir administrado como dosis única diaria de $900 \mathrm{mg}$ tiene la misma eficacia que ganciclovir oral a dosis de 1.000 mg cada 8 horas como profilaxis de la enfermedad por CMV en receptores de alto riesgo de TOS $^{87}$. Aunque el riesgo de neutropenia es mayor con valganciclovir $(8,2 \%$ vs $3,2 \%$ ), el perfil de seguridad es equiparable, la tolerancia oral es mejor con valganciclovir y la incidencia de viremia durante la profilaxis y después de la misma, fue significativamente menor en los paciente tratados con valganciclovir que en los tratados con ganciclovir oral ${ }^{87}$.

El ganciclovir oral, con una biodisponibilidad oral del $7 \%$, unas 10 veces inferior a valganciclovir, sigue siendo un fármaco activo en la profilaxis frente a $\mathrm{CMV}^{88}$, con actividad similar a valganciclovir $^{87}$, y mayor que con aciclovir (800 $\mathrm{mg} / 6 \mathrm{~h})^{89,90}$ y que con placebo ${ }^{91}$. El ganciclovir puede asimismo administrarse por vía intravenosa durante toda la profilaxis o como pauta de inicio. En este sentido, en un estudio randomizado y controlado ${ }^{92}$ en pacientes seronegativos receptores de trasplante hepático de donante seropositivo, no se objetivan diferencias en cuanto a enfermedad por CMV a un año postrasplante, se haya realizado la profilaxis con ganciclovir intravenoso o con tratamiento secuencial de ganciclovir intravenoso y oral. En conclusión, las guías de consenso recomiendan el tratamiento secuencial para la prevención de la enfermedad por $\mathrm{CMV}^{82,93}$.

La gammaglobulina hiperinmune específica es un producto preparado de suero humano que contiene altas concentraciones de anticuerpos frente a CMV. Aunque puede que disminuya los efectos inmunosupresores inducidos por el CMV, su eficacia no está bien establecida ya que se usa en combinación con un antiviral. Otras estrategias terapéuticas vienen representadas por la leflunomida, un inmunosupresor de administración vía oral, inhibidor de la síntesis de pirimidinas, que tiene un efecto antiviral interfiriendo el ensamblaje de los viriones. A través de este mecanismo es capaz de disminuir la replicación de CMV y de virus herpes simple tipo ${ }^{9496}$. 


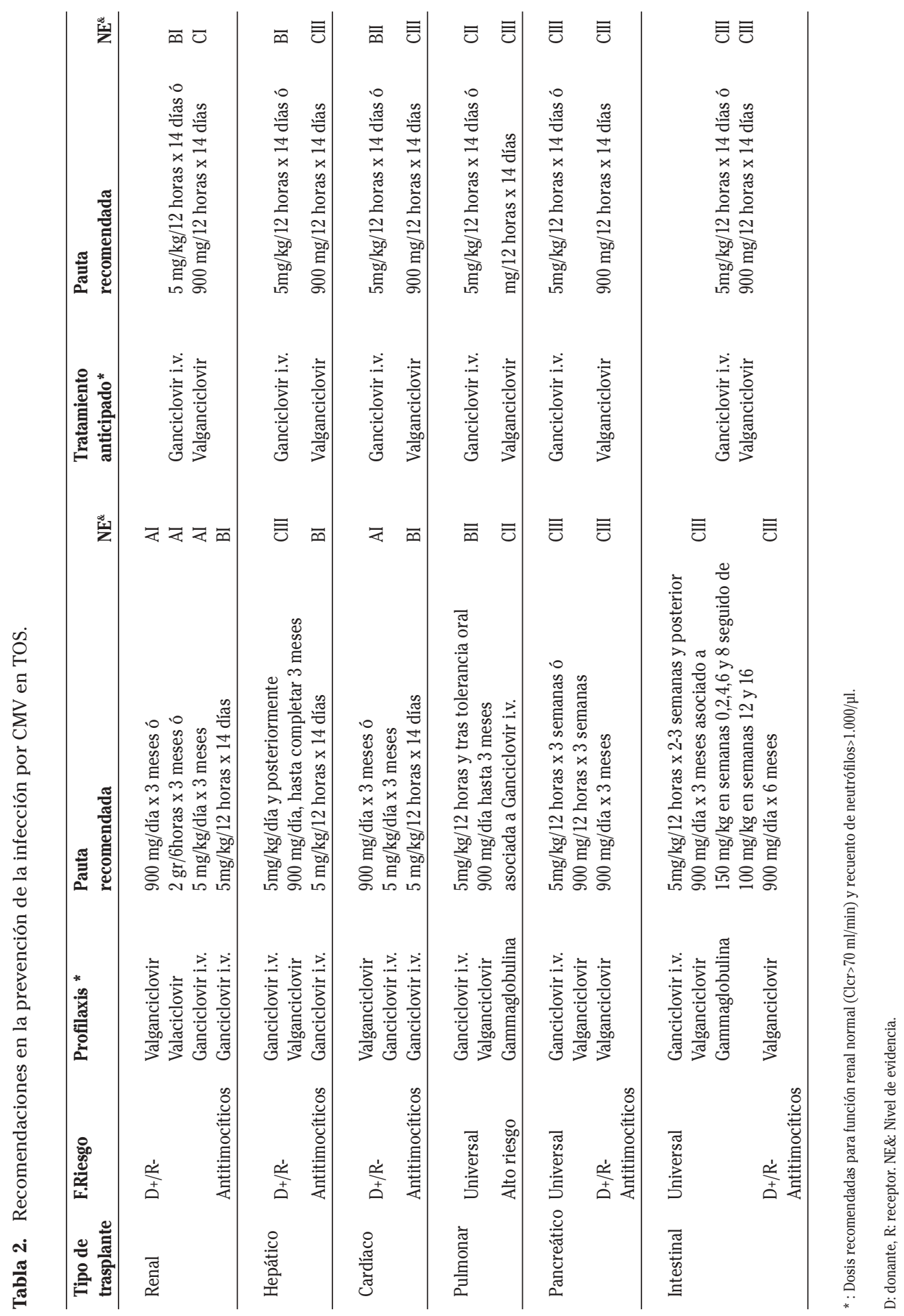


La duración óptima de la profilaxis antiviral debe establecerse mediante estudios controlados. No obstante, la mayoría de los autores recomiendan mantenerla durante 100 días y pautas más recortadas no ofrecen resultados superiores a placebo. Sus beneficios parecen estar limitados al período de administración por lo que, tras completar la profilaxis correcta, persiste el riesgo de enfermedad por CMV, y debe seguir monitorizándose el CMV en sangre $^{93}$.

Respecto al tratamiento anticipado de la infección por CMV, pocos estudios randomizados han evaluado la eficacia del tratamiento anticipado en cuando a prevenir la enfermedad por CMV si bien sí que es superior al placebo ${ }^{97}$. En un estudio randomizado, doble ciego ${ }^{98}$, el ganciclovir oral a dosis de $1.000 \mathrm{mg} / 8 \mathrm{~h}$ es capaz de disminuir la incidencia de enfermedad por CMV y disminuir la viremia en trasplantados hepáticos. Sin embargo, no es eficaz en pacientes con replicación viral elevada en el momento del inicio del tratamiento. Por este motivo no debe utilizarse en estos pacientes, ya que además puede inducir la aparición de resistencias farmacológicas. La eficacia de valganciclovir debe evaluarse prospectivamente en estudios randomizados ${ }^{93}$. Al igual que en el TPH la combinación de foscarnet y ganciclovir intravenoso, ambos a mitad de dosis, a los 14 días de tratamiento, no mejora los resultados de ganciclovir a dosis plena y en cambio si que aumenta los efectos secundarios. En este sentido no parece que exista una sinergia entre ambos antivirales ${ }^{72}$.

\section{Tratamiento de la enfermedad por CMV}

Aunque no existen estudios controlados, el ganciclovir intravenoso a dosis de 5 $\mathrm{mg} / \mathrm{kg} / 12 \mathrm{~h}$ constituye el tratamiento de elección ${ }^{99}$. La resistencia a ganciclovir es un problema emergente en pacientes que han recibido profilaxis con este antiviral durante tiempo prolongado y, en ocasiones, con niveles infraterapéuticos. En estos casos de resistencia, la asociación de ganciclovir y foscarnet, a dosis plena, ha resultado eficaz ${ }^{100}$.
Valganciclovir parece una forma lógica de continuación del tratamiento iniciado con ganciclovir intravenoso. Si bien no existen estudios clínicos aleatorios publicados, en pacientes con trasplante renal y enfermedad por CMV el tratamiento con valganciclovir hasta la resolución de la antigenemia fue satisfactorio y no se siguió de recidiva ${ }^{101}$. Una dosis de $900 \mathrm{mg}$ es equiparable (área bajo la curva) a una dosis de $5 \mathrm{mg} / \mathrm{kg}$ de ganciclovir intravenoso. Foscarnet está indicado en pacientes con resistencia clínica a ganciclovir, aparición de enfermedad bajo profilaxis con ganciclovir o valganciclovir y en pacientes con contraindicación para tratamiento con ganciclovir por neutropenia. Se administra a dosis de $60 \mathrm{mg} / \mathrm{kg} / 8 \mathrm{~h}$ o $90 \mathrm{mg} / \mathrm{kg} / 12 \mathrm{~h}^{99}$. Cidofovir es un fármaco de segunda línea que, a dosis de $3-5 \mathrm{mg} / \mathrm{kg} / \mathrm{semana}$, puede utilizarse en casos de resistencia a ganciclovir y foscarnet. Sin embargo, en situaciones de alta resistencia al ganciclovir, en relación con alteraciones del gen de la polimerasa, existe resistencia cruzada al cidofovir ${ }^{102}$. Existen otros antivirales en estudio como adefovir, benzimidazol, lobucavir y maribavir y otros en desarrollo preclínico como tomeglovir y CMV423.

No hay una recomendación establecida respecto a la duración del tratamiento, si bien suele mantenerse entre 3 y 4 semanas.

\section{Otros virus}

\section{Virus de Epstein-Barr}

El riesgo de infección por VEB es variable según el nivel de inmunosupresión, la presencia de infección por CMV y del estatus serológico del donante y del receptor, siendo considerada de alto riesgo la situación donante seropositivo/receptor seronegativo. Dada su implicación en la aparición de SLP en el postrasplante, muchos centros adoptan estrategias para disminuir la replicación viral con fármacos antivirales como ganciclovir y aciclovir y con inmunoglobulinas para prevenir la infección de los linfocitos B. No obstante ni las inmunoglobulinas ni los antivirales, que solo son efectivos inhibiendo la replicación viral, parece que tengan efecto sobre el control de las enfermedades asociadas ${ }^{103}$. 
La primera línea de tratamiento consiste en disminuir la inmunosupresión para recuperar la respuesta específica de linfocitos $\mathrm{T}$ citotóxicos frente a $\mathrm{VEB}^{104}$. Dado que existe una relación entre carga viral de VEB y SLP, en pacientes de alto riesgo, se recomienda monitorización semanal de la carga viral durante 6 meses y en caso de detectarse reactivación iniciar tratamiento anticipado con anticuerpos monoclonales anti-CD2 $0^{105}$, anti-interleukina- $6^{106}$ o infusión de linfocitos T citotóxicos específicos frente a $\mathrm{VEB}^{107}$. Los resultados obtenidos en este sentido, son prometedores.

\section{Virus varicela-zóster}

Respecto a la profilaxis, en el TOS, no está indicada la profilaxis con antivirales ${ }^{108}$. En pacientes seronegativos la vacunación previa al trasplante es una opción válida, si bien tras la realización del mismo está contraindicada ${ }^{109}$. En casos de exposición al virus se recomienda profilaxis con inmunoglobulina hiperinmune específica.

En el TPH, en pacientes seronegativos con riesgo de desarrollar complicaciones (tiempo desde trasplante inferior a un año o mayor de un año con EICH aguda o crónica o en tratamiento inmunosupresor), expuestos a un caso de varicela o zóster, está indicada la profilaxis postexposición (antes de las 96 horas) con inmunoglobulina específica y puede valorarse según el riesgo el aciclovir profiláctico. En pacientes seropositivos no se recomienda profilaxis salvo que existan antecedentes de enfermedad grave ${ }^{110}$.

El tratamiento de elección es la administración de aciclovir intravenoso a dosis altas de $500 \mathrm{mg} / \mathrm{m}^{2} / 8 \mathrm{~h}$ durante $7-10$ días. Se debe de instaurar precozmente, ya que ha demostrado que detiene la progresión local y visceral, y disminuye la mortalidad ${ }^{111}$. Aunque su administración oral a dosis de $800 \mathrm{mg}$ cinco veces al día es una alternativa válida, esta vía suele utilizarse como tratamiento del zóster monometamérico sin factores de riesgo o como secuenciación del tratamiento intravenoso en pacientes con evolución favorable. A pesar de que existe una escasa experiencia en inmunodeprimidos, la administración de famciclovir a dosis de $500 \mathrm{mg} / 8 \mathrm{~h}$ o de valaciclovir a dosis de $1.000 \mathrm{mg} / 8 \mathrm{~h}$, podrían ser alternativas válidas a la vía oral, con una mejor posología y una buena tolerancia ${ }^{110}$.

\section{Virus herpes simple}

En los pacientes sometidos a TPH la profilaxis con aciclovir está indicada en todos los receptores alogénicos seropositivos, para prevenir la reactivación del VHS y no está indicada en receptores seronegativos, aunque el donante sea seropositivo. La profilaxis con aciclovir se inicia por vía intravenosa $\left(250 \mathrm{mg} / \mathrm{m}^{2} / 12 \mathrm{~h}\right)$ y posteriormente, cuando existe tolerancia oral, a dosis de $400 \mathrm{mg}$, cinco veces al día, con igual eficacia. El aciclovir se mantiene durante 30 días, que es el tiempo que transcurre hasta el prendimiento del injerto o remisión de la mucositis. No se recomienda mantener el aciclovir más de 30 días, salvo si existen antecedentes de recurrencias frecuentes. En estos casos se establece profilaxis secundaria con aciclovir oral (200 $\mathrm{mg} / 8-12 \mathrm{~h}$, durante 6 meses). Los pacientes que reciben ganciclovir, foscarnet o cidofovir como prevención de infección por CMV, no requieren profilaxis con aciclovir dado que estos antivirales son activos frente a VHS. El valaciclovir puede considerarse como alternativa y sobre el famciclovir no se pueden realizar recomendaciones ya que no existen datos suficientes. El foscarnet, en base a su toxicidad renal, no debe recomendarse como profilaxis ${ }^{112}$.

En los receptores de TOS debe establecerse profilaxis con aciclovir, valaciclovir o famciclovir en los receptores seropositivos y con infecciones de repetición. La profilaxis debe mantenerse de tres a seis meses, durante los períodos de intensificación de la inmunosupresión y ante situaciones de infección concomitante o cirugía. Al igual que en el TPH, la profilaxis frente a CMV es eficaz frente a VHS.

La infección sintomática local se trata con aciclovir oral a dosis de $200 \mathrm{mg}$ cinco veces al día durante 7-10 días. Famciclovir y valaciclovir son opciones válidas. En caso de infección diseminada se utiliza aciclovir oral a dosis más altas de $800 \mathrm{mg}$ cinco veces al día o por vía intravenosa a dosis de $10 \mathrm{mg} / \mathrm{kg} / 8 \mathrm{~h}$. En casos de resistencia a aciclovir debe utilizarse foscarnet 
a dosis de $40 \mathrm{mg} / \mathrm{kg} / 8 \mathrm{~h}$, por vía parenteral $\mathrm{y}$, en casos de doble resistencia, la única opción terapéutica es el cidofovir (eficaz in vitro pero con respuesta clínica variable). Además, la reconstitución inmune parece ser necesaria para la erradicación de la infección ${ }^{113}$.

\section{Virus del herpes humano tipo 6}

In vitro es resistente a aciclovir a los niveles alcanzables in vivo. Actualmente no existe un tratamiento para la infección por VVH-6, aunque en general, se recomienda el ganciclovir como primera opción. In vitro, foscarnet ha mostrado ser más eficaz que el aciclovir o el ganciclovir. La disminución de la inmunosupresión se asocia con una menor actividad replicativa del virus ${ }^{114,115}$. Aunque no existen datos suficientes, el ganciclovir a dosis profiláctica probablemente no sea eficaz para prevenir la reactivación de este virus. Respecto al valganciclovir, todavía no hay datos disponibles a cerca de su utilidad.

\section{Virus del herpes humano tipo 7}

La sensibilidad del VHH-7 a los antivirales es poco conocida. Aunque in vitro foscarnet, cidofovir, CADA y PMPA inhiben la replicación del VHH-7, por las concentraciones alcanzadas, solo el ganciclovir y el cidofovir parecen ser activos in vivo ${ }^{116}$.

\section{Parvovirus b19}

No existe tratamiento antiviral con actividad frente al parvovirus B19. Aparte del tratamiento sintomático, el tratamiento con inmunoglobulinas favorece la resolución del cuadro ${ }^{117,118}$.

\section{Poliomavirus (Virus BK y JC)}

Actualmente no existe ningún tratamiento farmacológico ni estrategia de profilaxis medicamentosa. La disminución de la terapia inmunosupresora es la única opción disponible para su control.

\section{Virus respiratorios (Influenza, Parainfluenza, Virus sincitial respiratorio, Adenovirus)}

La vacunación anual frente a Influenza es el único método eficaz para controlar la enfermedad. La infección, no así la vacunación, se asocia con un aumento en la tasa de rechazos $^{119}$. La vacuna debe administrarse tanto al paciente como a los convivientes y al staff responsable. Debe pautarse previo al trasplante y posteriormente, a partir del sexto mes, con periodicidad anual al menos durante 24 meses en el TPH y de modo indefinido en el TOS. Amantadina y rimantadina son muy eficaces en la prevención de influenza A y los inhibidores de la neuraminidasa (oseltamivir y zanamivir) frente a influenza $\mathrm{A}$ y $\mathrm{B}^{112}$. No deben utilizarse de forma rutinaria, si bien ante una epidemia de influenza A y tras un contacto con individuos afectos, puede considerarse quimioprofilaxis con amantadina o rimamtidina, principalmente en pacientes trasplantados con una evolución inferior a 6 meses. Respecto al virus respiratorio sincitial, se han propuesto estrategias para prevenir su progresión al tracto respiratorio inferior, como son la ribavirina en aerosoles, sola o en combinación con anticuerpos específicos o palivizumab. No existen recomendaciones firmes sobre estas pautas ${ }^{112}$ ni tampoco existe una pauta terapéutica establecida frente a adenovirus.

\section{Infecciones bacterianas}

En el TPH las infecciones bacterianas representan una grave complicación, principalmente durante la neutropenia asociada a la citoreducción, en las infecciones de catéteres venosos centrales y en la EICH. Deben valorarse las guías terapéuticas establecidas para el tratamiento de estas infecciones considerando los patógenos habituales. Asimismo, deben establecerse las pautas de profilaxis quirúrgica recomendadas para cada tipo de TOS. El lavado de manos constituye una maniobra de profilaxis universal frente a las infecciones bacterianas. La profilaxis frente a organismos encapsulados (frecuentes en la EICH) como son $S$. pneumoniae, $H$. influenzae y $N$. meningitis debe establecerse mediante las pautas de vacunación establecidas y el tratamiento en base a los patrones de resistencia local. La mucositis puede facilitar la traslocación de $S$. viridans de la boca a la sangre, por lo que se recomienda una valoración dental, principalmente en el TPH. 


\section{Listeria monocytogenes}

La infección por Listeria monocytogenes es poco frecuente, en parte por la profilaxis establecida con cotrimoxazol frente a Pneumocystis jiroveci. En cuanto al tratamiento, la ampicilina es el fármaco de elección. En pacientes con inmunosupresión con disminución de la función de los linfocitos $\mathrm{T}$ y en todos los casos de meningitis y endocarditis se recomienda la asociación de gentamicina por el efecto sinérgico que existe entre ambos. En casos de alergia y/o intolerancia a penicilinas, el cotrimoxazol representa la mejor alternativa. Además, existen estudios en los que el fracaso terapéutico en meningoencefalitis severa es menor con la combinación de ampilicilina con cotrimoxazol que cuando la primera se combina con un aminoglucósido. No se aconseja el uso de cefalosporinas. Vancomicina es una alternativa terapéutica, si bien nuevos glicopépticos como la dalbavancina ${ }^{120}$, oxazolidonas como el linezolid (en meningoencefalitis, dada su buena penetración en SNC) ${ }^{121}$, o la daptomicina (en casos de endocarditis) ${ }^{122}$ tienen un alto potencial terapéutico. Cloranfenicol tiene un riesgo elevado de fracaso y recidivas y sobre la rifampicina la experiencia clínica es mínima ${ }^{123}$. El tratamiento debe mantenerse un mínimo de 3 semanas cuando la infección se localiza en SNC, 2 semanas en la bacteriemia y 4-6 semanas en la endocarditis. Debe evitarse el uso de corticoides por el deterioro de la inmunidad celular y por ser un factor de riesgo de desarrollo de listeriosis.

\section{Nocardia asteroides}

El cotrimoxazol es el fármaco de elección en cualquiera de sus formas de presentación. Puede combinarse con imipenem (efecto aditivo) o con amikacina (efecto sinérgico), ambos con gran actividad frente a $N$. asteroides. Las cefalosporinas de tercera generación, principalmente ceftriaxona, por su alta penetración en líquido cefalorraquídeo y su baja toxicidad, es el fármaco de elección a combinar con cotrimoxazol en la afectación de SNC. Meropenem es una buena alternativa, mejor que imipenem, por su buena penetración y menor riesgo de incidencia de crisis epilépticas. La alternativa oral al cotrimoxazol es la minociclina, si bien linezolid presenta una gran actividad frente a Nocardia $\mathrm{spp}^{124}$. El tratamiento en pacientes trasplantados inmunosuprimidos debe prolongarse durante 12 meses. Durante el primer mes debe realizarse biterapia y por vía intravenosa y posteriormente vía oral en monoterapia con cotrimoxazol como fármaco de primera elección.

\section{INFECCIONES FÚNGICAS}

Las infecciones fúngicas en el trasplante, son una complicación grave y, aunque su incidencia es inferior que las bacterianas o víricas, su mortalidad es mucho mayor.

\section{Trasplante de progenitores hematopoyéticos (TPH)}

Dado que la infección por Candida spp. casi siempre tiene un origen endógeno, la profilaxis antifúngica pretende descontaminar el aparato digestivo. Éste constituye la principal puerta de entrada de las infecciones por Candida spp. debido a la alteración de las barreras mucosas que ocurre durante las fases de neutropenia. Fluconazol se ha mostrado claramente eficaz ${ }^{125}$ a pesar de no ser efectivo frente a algunas especies cómo Candida glabrata o Candida krusei, e interferir con los sistemas enzimáticos hepáticos dependientes del citocromo P-450. La dosis habitualmente utilizada es la de $400 \mathrm{mg} /$ día y se mantiene hasta el día +75 postrasplante ${ }^{125,126}$. Con esta pauta fluconazol reduce la incidencia de infecciones por Candida spp., la mortalidad relacionada a corto y largo plazo, la incidencia de EICH intestinal grave y, en su conjunto, mejora la supervivencia ${ }^{126}$. Aunque dosis menores, entre 50 y $200 \mathrm{mg} /$ día, también parecen ser eficaces, hay menos experiencia con su uso y no se recomiendan en pacientes de alto riesgo ${ }^{127}$. Con todo lo anteriormente expuesto, fluconazol debería recomendarse profilácticamente en los receptores de un TPH autólogo o alogénico en el que se prevea neutropenia prolongada, presenten mucositis intensa o hayan recibido recientemente análogos de las purinas ${ }^{128}$.

Como fluconazol no tiene actividad frente a hongos filamentosos y especial- 
mente frente a Aspergillus spp. se ha evaluado la actividad de itraconazol como profilaxis de la infección fúngica invasiva (IFI). En el trabajo publicado por Marr y $\mathrm{col}^{129}$ en 2004, se compara itraconazol en solución oral (2,5 mg/kg/8horas) o intravenoso (200 mg/día) frente a fluconazol (400 $\mathrm{mg} /$ día) como profilaxis de infección fúngica en pacientes sometidos a TPH alogénico. La incidencia de IFI fue menor en el grupo de itraconazol ( $7 \%$ vs $15 \%$ ) y similar frente a candidiasis ( $2 \%$ vs $3 \%$ ). No hubo diferencias en cuanto a supervivencia y el número de abandonos por intolerancia al itraconazol (toxicidad gastrointestinal y/o hepática) fue notablemente superior que con fluconazol (36\% vs 16\%). Con todo esto parece prudente realizar profilaxis con itraconazol a pacientes con alto riesgo de IFI. Dadas las dificultades para su correcto cumplimiento debe de valorarse la utilización de otros azoles con actividad frente a hongos filamentosos, algunos ya disponibles como el voriconazol y otros como posaconazol y ravuconazol que proximamente lo estarán.

Micafungina, una equinocandina con actividad frente a Candida spp y Aspergillus spp, ha sido evaluada como pauta profiláctica en el TPH durante la neutropenia a dosis de $50 \mathrm{mg} /$ día frente a 400 $\mathrm{mg} /$ día de fluconazol. Durante la fase neutropénica la eficacia de micafungina fue superior a fluconazol ( $80 \%$ vs $74 \%$ ) al igual que una mejor eficacia frente a Aspergillus $(\mathrm{p}=0,07)^{130}$. Todo ello no se traduce en una mejora de la supervivencia.

Respecto a la anfotericina, los dos estudios prospectivos multicéntricos randomizados con vistas a evaluar la anfotericina B en aerosoles para la prevención de aspergilosis invasiva no han mostrado un beneficio significativo ${ }^{131,132}$, por lo que no se recomienda su uso.

El tratamiento anticipado consiste en la administración de fármacos cuando se detecta positividad de pruebas microbiológicas indicativas de infección en pacientes asintomáticos. Anfotericina B se recomienda para pacientes que son colonizados con los hongos resistentes a fluconazol y/o tienen dos pruebas positivas consecutivas para antigenemia de Aspergillus o PCR. Itra- conazol también puede indicarse en pacientes colonizados con Aspergillus spp. Si las cultivos son positivos para una levadura que no sea una Candida glabrata o una Candida krusei, se recomienda fluconazol o itraconazol (400 mg/ día, vía oral), empezando el primer día de neutropenia y continuando hasta que la inmunosupresión se haya resuelto ${ }^{133}$.

Respecto al tratamiento de la enfermedad establecida, deben seguirse las guías terapéuticas recomendadas.

\section{Trasplante de órgano sólido (TOS)}

Existen diversas pautas de profilaxis según el tipo de trasplante. En el trasplante reno-pancreático se realiza profilaxis universal frente a Candida spp. con fluconazol y en el trasplante hepático, sólo en situaciones de alto riesgo (reintervención, transfusiones masivas, colonización fúngica pretrasplante, uso de antibióticos, estancia prolongada en UCI, insuficiencia renal o disfunción del injerto). La dosis habitual de fluconazol son $200 \mathrm{mg} /$ día y se mantiene un período de 4 semanas. En un meta-análisis publicado en $2004^{134}$ que incluye 14 estudios randomizados sobre la eficacia de la prevención de la infección fúngica en el TOS se concluye que: 1 . la profilaxis antifúngica no reduce la mortalidad; 2 . en el trasplante hepático el fluconazol reduce significativamente la IFI; 3 . itraconazol y anfotericina B liposomal tienen una eficacia similar al fluconazol y; 4 . en receptores de trasplante renal y/o cardíaco, ni ketoconazol ni clotrimazol reducen significativamente la infecciones invasivas.

En el trasplante pulmonar y cardiopulmonar se emplea profilaxis frente a Candida spp. con fluconazol y frente a Aspergillus spp. con anfotericina B deoxicolato (ABD) inhalada. La anfotericina B complejo lipídico tiene una eficacia $\operatorname{similar}^{135}$ y la anfotericina B liposomal, dadas las altas concentraciones que consigue a nivel de parénquima pulmonar es una estrategia a considerar ${ }^{136}$. En este tipo de trasplante se ha evaluado en estudios no controlados la eficacia de itraconazol frente a flucona$\mathrm{zol}^{137}$ o como pauta profiláctica tras anfotericina aerosolizada ${ }^{138}$, mostrando en ambos 
casos una reducción en la incidencia de aspergilosis invasiva.

Aunque voriconazol y caspofungina tienen una excelente actividad frente a Candida spp y a Aspergillus spp., hasta la fecha no existen estudios clínicos que avalen su utilización en la profilaxis antifúngica. A pesar de ello caspofungina puede considerarse como una alternativa al fluconazol para la profilaxis frente a Candida spp. y el voriconazol una alternativa a la anfotericina y al itraconazol en la profilaxis frente a Aspergillus spp. y a Candida spp. Asimismo, no deben olvidarse las limitaciones para su uso como la hepatotoxicidad y las interacciones con inmunosupresores $\mathrm{y}$ que contraindican la combinación de voriconazol con sirolimus (aumenta los niveles de sirolimus 3-5 veces) y de caspofungina con ciclosporina A (aumenta la AUC de caspofungina).

Respecto al tratamiento de la enfermedad establecida, al igual que el TPH, deben seguirse las guías terapéuticas recomendadas.

\section{Pneumocystis jiroveci}

El riesgo de infección por $P$. jiroveci depende de la intensidad y duración de la inmunosupresión así como de la presencia de posibles déficits inmunológicos. La profilaxis primaria es beneficiosa en el trasplante pulmonar, en individuos con enfermedad por CMV, durante la inmunosupresión intensa por rechazo, durante los períodos de neutropenia, en el TPH alogénico y en el TPH autólogo ante determinadas enfermedades hematológicas como linfoma, mieloma o leucemia o en pacientes con manipulación del injerto (selección CD34) o que han recibido análogos de purinas ${ }^{139}$.

El fármaco de elección para la profilaxis es el trimetoprim-sulfametoxazol a dosis doble $(160 \mathrm{mg} / 800 \mathrm{mg})$ tres veces por semana, durante 6-12 meses. En los pacientes sometidos a trasplante pulmonar, en los que tienen dosis altas y mantenidas de inmunosupresión y en los que presentan infección viral crónica, la profilaxis puede prolongarse por encima de los 12 meses ${ }^{140}$. Además, cotrimoxazol también ejerce un efecto protector frente a
Toxoplasma gondii, infección respiratoria adquirida en la comunidad, infección gastrointestinal y del tracto urinario ${ }^{139}$. Existen alternativas terapéuticas como la dapsona o la pentamidina inhalada mensual, ambos con un espectro mas estrecho y menor protección frente a Pneumocystis jiroveci por lo que debe de considerarse la desensibilización a cotrimoxazol.

El tratamiento de primera elección es cotrimoxazol a dosis elevadas de 20 $\mathrm{mg} / \mathrm{kg} /$ día de trimetoprim y $100 \mathrm{mg} / \mathrm{kg} /$ día de sulfametoxazol durante 2 semanas. No existen estudios clínicos controlados que avalen el uso concomitante de corticoides. Como alternativas terapéuticas figuran pentamidina intravenosa a dosis de 4 $\mathrm{mg} / \mathrm{kg} /$ día, atovaquona, clindamicina junto con primaquina y dapsona más trimetoprim. La caspofungina, micafungina y anidulafungina también tienen actividad frente a Pneumocystis jiroveci.

\section{INFECCIONES POR PROTOZOOS}

\section{Toxoplasma gondii}

Debe considerarse profilaxis en los pacientes sometidos a TPH con antecedentes de toxoplasmosis invasiva, principalmente en los que han tenido coriorretinitis y pacientes seropositivos con EICH aguda. En el TOS los pacientes de alto riesgo son los trasplantados cardíacos y hepáticos seronegativos de donante seropositivo. La pauta recomendada es el cotrimoxazol (160/800 mg, tres veces a la semana) y la alternativa es la clindamicina-pirimetamina o pirimetamina-sulfadoxina. La profilaxis se mantiene durante 6-8 semanas o mientras dura la profilaxis frente a $P$. jiroveci.

\section{VACUNACIÓN EN PACIENTES ADULTOS SOMETIDOS A TOS Y TPH}

Algunas de las infecciones que pueden aparecer en el paciente trasplantado pueden prevenirse mediante vacunas. Además, algunas de estas infecciones víricas, en principio prevenibles con la vacunación, pueden favorecer la aparición de fenómenos de rechazo.

En el TOS (Tabla 3), lo ideal es su administración antes del trasplante, y además, lo 
Tabla 3. Vacunas recomendadas en candidatos y receptores de TOS, en sus contactos familiares (CF) y en el personal sanitario (PS) que los atiende.

\begin{tabular}{|c|c|c|c|c|c|c|c|c|}
\hline \multirow[t]{2}{*}{ Vacuna } & \multicolumn{4}{|c|}{$\begin{array}{l}\text { Calendario } \\
\text { (meses) }\end{array}$} & \multirow[t]{2}{*}{$\begin{array}{l}\text { Antes } \\
\text { de TOS }\end{array}$} & \multirow[t]{2}{*}{$\begin{array}{l}\text { Después } \\
\text { de TOS }\end{array}$} & \multirow[t]{2}{*}{$\begin{array}{l}\text { Monitorización } \\
\text { de títulos }\end{array}$} & \multirow[t]{2}{*}{ CF y PS } \\
\hline & 0 & 1 & 2 & 6 & & & & \\
\hline Difteria-Tétanos & * & * & & * & SÍ & SÍ & NO & Sí \\
\hline Poliomielitis inactivada & * & & & & Sí & Sí & NO & Sí \\
\hline Neumococo & * & & & & Sí & Sí & Sí & Sí \\
\hline H. influenzae $B^{s}$ & * & & * & & Sí & Sí & NO & Sí \\
\hline Meningococo & * & & & & SÍ & SÍ & NO & SÍ \\
\hline Gripe* $^{*}$ & * & & & & Sí & Sí & NO & Sí \\
\hline Hepatitis A & * & & * & & Sí & SÍ & Sí & Sí \\
\hline Hepatitis B\& & * & * & & * & Sí & Sí & Sí & Sí \\
\hline Varicela & * & & & & Sí & NO & Sí & Sí \\
\hline Triple vírica & * & & & & SÍ & NO & SÍ & Sí \\
\hline
\end{tabular}

Vacunas polisacáridas: Neumococo (23 serotipos), H.influenzae serotipo b y Meningococo.

$\$$ :Principalmente se recomienda en niños y en adultos sometidos a trasplante cardiaco, pulmonar o cardiopulmonar.

*: Se administra con periodicidad anual.

\&:Si se requiere protección rápida la dosis del sexto mes puede administrarse al segundo mes.

antes posible. Si no se ha podido completar la pauta de vacunación antes del trasplante, ésta puede completarse a partir del sexto mes, salvo en el caso de las vacunas atenuadas con agentes vivos (triple vírica, varicela, polio oral, fiebre tifoidea oral, gripe intranasal, BCG y fiebre amarilla) que están contraindicadas en el postrasplante ${ }^{141}$.

En los pacientes con TPH (Tabla 4) se produce una pérdida de la inmunidad tras

Tabla 4. Vacunas recomendadas en receptores de TPH, en sus contactos familiares (CF) y en el personal sanitario (PS) que los atiende.

\begin{tabular}{|c|c|c|c|c|c|}
\hline \multirow[t]{2}{*}{ Vacuna } & \multicolumn{3}{|c|}{ Calendario (meses) } & \multirow{2}{*}{$\begin{array}{c}\text { Monitorización } \\
\text { de títulos }\end{array}$} & \multirow[t]{2}{*}{ CF y PS } \\
\hline & $6 \quad 12$ & 14 & 24 & & \\
\hline Difteria-Tétanos & * & $*$ & * & NO & Sí \\
\hline Difteria-Tétanos-Tosferina ( $<$ 7años) & * & * & * & & \\
\hline Poliomielitis inactivada & * & * & * & NO & Sí \\
\hline Neumococo & * & & * & Sí & Sí \\
\hline H. influenzae B & * & * & * & NO & Sí \\
\hline Meningococo $^{\circledR}$ & * & & * & NO & Sí \\
\hline Gripe* $^{*}$ & * & & & NO & Sí \\
\hline Hepatitis $A^{\#}$ & * & * & & Sí & Sí \\
\hline Hepatitis B & * & * & * & Sí & Sí \\
\hline Varicela ${ }^{\$}$ & & & & & SÍ \\
\hline Triple vírica & & & * & Sí & Sí \\
\hline
\end{tabular}

Vacunas polisacáridas: Neumococo (23 serotipos), H.influenzae serotipo b y Meningococo.

@: No existe información sobre el uso de esta vacuna. Puede plantearse un esquema similar a la vacuna del neumococo.

* : Se administra con periodicidad anual.

\# : No existe información sobre su recomendación. Valorar en enfermedad hepática y EICH o concurrencia con otras hepatitis virales.

$\$$ : No se recomienda su uso. Se recomienda vacunación en CF y PS. 
la realización del trasplante y se admite una recuperación completa de la capacidad de respuesta a los dos años del trasplante, en ausencia de EICH. En todos los casos de TPH está indicado un programa de reinmunización. Se recomienda iniciar la pauta a partir de los doce meses del trasplante, salvo en el caso de la vacuna de la gripe que se pauta a partir del sexto mes. En las vacunas con virus atenuados, la triple vírica sólo puede administrarse en pacientes inmunocompetentes tras 24 meses del trasplante, que no han recibido drogas inmunosupresoras y no tienen EICH. Respecto a la varicela, actualmente no existen datos suficientes como para recomendar esta vacuna ${ }^{112}$.

\section{BIBLIOGRAFIA}

1. Aguado JM, Herrero JA, GaValda J, Torre-Cisneros J, Blanes M, RuFi G et al. Clinical presentation and outcome of tuberculosis in kidney, liver, and heart transplant recipients in Spain. Spanish Transplantation Infection Study Group, GESITRA. Transplantation 1997; 63: 1278-1286.

2. AlKan S, Karcher DS, Ortiz A, Khalil S, AKhtar M, ALI MA. Human herpesvirus-8/Kaposi's sarcoma-associated herpesvirus in organ transplant patients with immunosuppression. Br J Haematol 1997; 96: 412-414.

3. AtKinson K, Nivison-Smith I, Dodds A, ConcanNON A, Milliken S, Downs K. A comparison of the pattern of interstitial pneumonitis following allogeneic bone marrow transplantation before and after the introduction of prophylactic ganciclovir therapy in 1989. Bone Marrow Transplant 1998; 21: 691-695.

4. Berenguer J, Gomez-Campdera F, Padilla B, Rodriguez-Ferrero M, ANAYA F, Moreno S et al. Visceral leishmaniasis (Kala-Azar) in transplant recipients: case report and review. Transplantation 1998; 65: 1401-1404.

5. Boubenider S, Hiesse C, Marchand S, Hafi A, KriAA F, ChARPENTIER B. Post-transplantation polyomavirus infections. J Nephrol 1999; 12: 24-29.

6. BRAUN WE. Long-term complications of renal transplantation. Kidney Int 1990; 37: 13631378.

7. Briz M, Fores R, Regidor C, Busto MJ, RAMON Y CAJAL S, CABrera R et al. Epstein-Barr virus associated B-cell lymphoma after autologous bone marrow transplantation for T-cell acute lymphoblastic leukaemia. Br J Haematol 1997; 98: 485-487.
8. Chang FY, Singh N, Gayowski T, Wagener MM, MARINO IR. Fever in liver transplant recipients: changing spectrum of etiologic agents. Clin Infect Dis 1998; 26: 59-65.

9. CHOU SW. Neutralizing antibody responses to reinfecting strains of cytomegalovirus in transplant recipients. J Infect Dis 1989; 160: 16-21.

10. DeVault GA, JR., King JW, Rohr MS, LandreNEAU MD, BROWN ST, 3RD, MCDONALD JC. Opportunistic infections with Strongyloides stercoralis in renal transplantation. Rev Infect Dis 1990; 12: 653-671.

11. Dummer JS, Hardy A, Poorsattar A, Ho M. Early infections in kidney, heart, and liver transplant recipients on cyclosporine. Transplantation 1983; 36: 259-267.

12. Duncan AJ, Dummer JS, PARAdis IL, DAuber JH, Yousem SA, Zenati MA et al. Cytomegalovirus infection and survival in lung transplant recipients. J Heart Lung Transplant 1991; 10(5 Pt 1): 638-44; discussion 645-646.

13. Eid AJ, Brown RA, Patel R, Razonable RR. Parvovirus B19 infection after transplantation: a review of 98 cases. Clin Infect Dis 2006; 43: 40-48.

14. Elting LS, Bodey GP, KeEfe BH. Septicemia and shock syndrome due to viridans streptococci: a case-control study of predisposing factors. Clin Infect Dis 1992; 14: 12011207.

15. Engelhard D, Elishoov H, Strauss N, Naparstek E, NAGLER A, SimHon A et al. Nosocomial coagulase-negative staphylococcal infections in bone marrow transplantation recipients with central vein catheter. A 5-year prospective study. Transplantation 1996; 61: 430-434.

16. Forbes GM, HaRvey FA, Philpott-Howard JN, O'GRADY JG, JENSEN RD, SAHATHEVAN M et al. Nocardiosis in liver transplantation: variation in presentation, diagnosis and therapy. J Infect 1990; 20: 11-19.

17. Girgis RE, Tu I, Berry GJ, Reichenspurner H, VAlEnTine VG, CONTE JV et al. Risk factors for the development of obliterative bronchiolitis after lung transplantation. J Heart Lung Transplant 1996; 15: 1200-1208.

18. Gomez E, Melon S, Aguado S, Sanchez JE, PorTAL C, FERNANDEZ A et al. Herpes simplex virus encephalitis in a renal transplant patient: diagnosis by polymerase chain reaction detection of HSV DNA. Am J Kidney Dis 1997; 30: 423-427.

19. Hanto DW, Frizzera G, Purtilo DT, SaKamoto K, Sullivan JL, Saemundsen AK et al. Clinical spectrum of lymphoproliferative disorders in renal transplant recipients and evidence 
for the role of Epstein-Barr virus. Cancer Res 1981; 41(11 Pt 1): 4253-4261.

20. Herbein G, Strasswimmer J, Altieri M, WoehlJAEGLE ML, Wolf P, OBert G. Longitudinal study of human herpesvirus 6 infection in organ transplant recipients. Clin Infect Dis 1996; 22: 171-173.

21. Holliman RE, Johnson JD, Adams S, Pepper JR. Toxoplasmosis and heart transplantation. J Heart Lung Transplant 1991; 10: 608-610.

22. Jarowski CI, Fialk MA, MurRay HW, Gottlieb GJ, Coleman M, Steinberg CR et al. Fever, rash, and muscle tenderness. A distinctive clinical presentation of disseminated candidiasis. Arch Intern Med 1978; 138: 544546.

23. John GT, Shankar V, ABraham AM, Mukundan U, THOMAS PP, JACOB CK. Risk factors for posttransplant tuberculosis. Kidney Int 2001; 60: 1148-1153.

24. Junghanss C, MARR KA. Infectious risks and outcomes after stem cell transplantation: are nonmyeloablative transplants changing the picture? Curr Opin Infect Dis 2002; 15: 347-353.

25. Kusne S, Dummer JS, Singh N, Iwatsuki S, MAKOWKA L, EsQuivel C et al. Infections after liver transplantation. An analysis of 101 consecutive cases. Medicine (Baltimore) 1988; 67: 132-143.

26. Kusne S, Manez R, Bonet H, Abu-Elmagd K, FURUKAWA H, IRISH W et al. Infectious complications after small bowel transplantation in adults. Transplant Proc 1994; 26: 1682-1683.

27. KWAK EJ, Vilchez RA, RandhaWa P, Shapiro R, Butel JS, Kusne S. Pathogenesis and management of polyomavirus infection in transplant recipients. Clin Infect Dis 2002; 35: 1081-1087.

28. LiCHTENSTEIN IH, MACGREgor RR. Mycobacterial infections in renal transplant recipients: report of five cases and review of the literature. Rev Infect Dis 1983; 5: 216-226.

29. LJUNGMAN P. Respiratory virus infections in bone marrow transplant recipients: the European perspective. Am J Med 1997; 102: 44-47.

30. LuUngman P, GRiffiths P, Paya C. Definitions of cytomegalovirus infection and disease in transplant recipients. Clin Infect Dis 2002; 34: 1094-1097.

31. Locasciulli A, Testa M, Pontisso P, Bacigalupo A, LJUngman P, FrickHofen $\mathrm{N}$ et al. Hepatitis C virus genotypes and liver disease in patients undergoing allogeneic bone marrow transplantation. Bone Marrow Transplant 1997; 19: $237-240$.
32. LoCKSLEy RM, Flournoy N, SuldivAn KM, MEyERS JD. Infection with varicella-zóster virus after marrow transplantation. J Infect Dis 1985; 152: 1172-1181.

33. Loinaz C, Moreno-Gonzalez E, Gomez R, Garcia I, Gonzalez-Pinto I, Jimenez $\mathrm{C}$ et al. Liver transplantation in liver disease: echinococcus granulosus. Transplant Proc 1998; 30: 3268-3269.

34. LOWRy PW, Blankenship RJ, GRidley W, TrouP NJ, Tompkins LS. A cluster of legionella sternal-wound infections due to postoperative topical exposure to contaminated tap water. N Engl J Med 1991; 324: 109-113.

35. Miller RB, Chavers BM. Respiratory syncytial virus infections in pediatric renal transplant recipients. Pediatr Nephrol 1996; 10: 213-215.

36. Nieto-Rodriguez JA, Kusne S, Manez R, IRISH W, LINDEN P, MAGNONE M et al. Factors associated with the development of candidemia and candidemia-related death among liver transplant recipients. Ann Surg 1996; 223: 70-76.

37. PATEL R, PAYA CV. Infections in solid-organ transplant recipients. Clin Microbiol Rev 1997; 10: 86-124.

38. Patel R, Portela D, Badley AD, Harmsen WS, LARSON-KELLER JJ, ILSTRUP DM et al. Risk factors of invasive Candida and non-Candida fungal infections after liver transplantation. Transplantation 1996; 62: 926-934.

39. PAYA CV, HERMANS PE. Bacterial infections after liver transplantation. Eur J Clin Microbiol Infect Dis 1989; 8: 499-504.

40. Perez MG, Vassilev T, Kemmerly SA. Rhodococcus equi infection in transplant recipients: a case of mistaken identity and review of the literature. Transpl Infect Dis 2002; 4: 52-56.

41. Peterson PK, ANDERSOn RC. Infection in renal transplant recipients. Current approaches to diagnosis, therapy, and prevention. Am J Med 1986; 81: 2-10.

42. PIRSCH JD, MAKI DG. Infectious complications in adults with bone marrow transplantation and T-cell depletion of donor marrow. Increased susceptibility to fungal infections. Ann Intern Med 1986; 104: 619-631.

43. Purighalla R, Shapiro R, Jordan ML, ScantleBURY VP, GRITSCH HA, VIVAS C et al. Acute renal allograft rejection in patients with EpsteinBarr virus associated post-transplant lymphoproliferative disorder. Clin Transplant 1997; 11: 574-576.

44. Ramsey PG, Fife KH, HaCKMAN RC, MEyers JD, COREY L. Herpes simplex virus pneumonia: clinical, virologic, and pathologic features in 
20 patients. Ann Intern Med 1982; 97: 813820.

45. RaO KV, KasisKe BL, ANDERSON WR. Variability in the morphological spectrum and clinical outcome of chronic liver disease in hepatitis B-positive and B-negative renal transplant recipients. Transplantation 1991; 51: 391396.

46. Roland M, Carlson L, Stock P. Solid organ transplantation in HIV-infected individuals. AIDS Clin Care 2002; 14: 59-63.

47. ROONEy CM, LOFTIN SK, HOLLADAY MS, BRENNER MK, KRANCE RA, HeSLOP HE. Early identification of Epstein-Barr virus-associated posttransplantation lymphoproliferative disease. Br J Haematol 1995; 89: 98-103.

48. SARR MG, GotT VL, TownSENd TR. Mediastinal infection after cardiac surgery. Ann Thorac Surg 1984; 38: 415-423.

49. Seprowitz KA, Brown AE, Telzak EE, Gottlieb S, ARmStrong D. Pneumocystis carinii pneumonia among patients without AIDS at a cancer hospital. Jama 1992; 267: 832-837.

50. Shah G, Demetris AJ, Gavaler JS, Lewis JH, Todo S, STARZl TE et al. Incidence, prevalence, and clinical course of hepatitis $\mathrm{C}$ following liver transplantation. Gastroenterology 1992; 103: 323-329.

51. Singh N, WAGENeR MM, MaRino IR, GAYOWSKi T. Trends in invasive fungal infections in liver transplant recipients: correlation with evolution in transplantation practices. Transplantation 2002; 73: 63-67.

52. Sollinger HW, KNeChtle SJ, ReEd A, D'AlessanDRO AM, Kalayoglu M, Belzer FO et al. Experience with 100 consecutive simultaneous kidney-pancreas transplants with bladder drainage. Ann Surg 1991; 214: 703-711.

53. Stehman-Breen CO, Psaty BM, Emerson S, Gretch D, Bronner M, MARSh C et al. Association of hepatitis $\mathrm{C}$ virus infection with mortality and graft survival in kidney-pancreas transplant recipients. Transplantation 1997; 64: 281-286.

54. Steiner M, Villablanca J, Kersey J, Ramsay N, HAAKE R, FERRIERI P et al. Viridans streptococcal shock in bone marrow transplantation patients. Am J Hematol 1993; 42: 354358.

55. Stolf NA, Higushi L, Bocchi E, Bellotti G, AULER JO, UIP D et al. Heart transplantation in patients with Chagas' disease cardiomyopathy. J Heart Transplant 1987; 6: 307-312.

56. StRASSER SI, MCDONALD GB. Hepatitis viruses and hematopoietic cell transplantation: A guide to patient and donor management. Blood 1999; 93: 1127-1136.
57. STRATTA RJ. Clinical patterns and treatment of cytomegalovirus infection after solidorgan transplantation. Transplant Proc 1993; 25: 15-21.

58. Turkmen A, Sever MS, Ecder T, Yildiz A, Aydin $\mathrm{AE}$, ЕRкос $\mathrm{R}$ et al. Posttransplant malaria. Transplantation 1996; 62: 1521-1523.

59. UMEKAWA T, KuRITA T. Acute hemorrhagic cystitis by adenovirus type 11 with and without type 37 after kidney transplantation. Urol Int 1996; 56: 114-116.

60. WaLd A, LeisenRING W, van BuRIK JA, Bowden RA. Epidemiology of Aspergillus infections in a large cohort of patients undergoing bone marrow transplantation. J Infect Dis 1997; 175: 1459-1466.

61. YoshiKawa T, Ihira M, Ohashi M, Suga S, Asano Y, MIYAZAKI $\mathrm{H}$ et al. Correlation between HHV6 infection and skin rash after allogeneic bone marrow transplantation. Bone Marrow Transplant 2001; 28: 77-81.

62. LuUngman P, BRand R, Einsele H, Frassoni F, NIEDERWIESER D, CORDONNIER C. Donor CMV serologic status and outcome of CMVseropositive recipients after unrelated donor stem cell transplantation: an EBMT megafile analysis. Blood 2003; 102: 42554260.

63. GoOdrich JM, Bowden RA, Fisher L, Keller C, SCHOCH G, MEYERS JD. Ganciclovir prophylaxis to prevent cytomegalovirus disease after allogeneic marrow transplant. Ann Intern Med. 1993; 118: 173-178.

64. Winston DJ, Ho WG, Bartoni K, Du Mond C, EBELING DF, BuHLES WC et al. Ganciclovir prophylaxis of cytomegalovirus infection and disease in allogeneic bone marrow transplant recipients. Results of a placebo-controlled, double-blind trial. Ann Intern Med. 1993; 118: 179-184.

65. BoeckH M, Gooley TA, Myerson D, Cunningham T, Schoch G, Bowden RA. Cytomegalovirus pp65 antigenemia-guided early treatment with ganciclovir versus ganciclovir at engraftment after allogeneic marrow transplantation: a randomized double-blind study. Blood. 1996; 88: 4063-4071.

66. Li CR, GREENBERG PD, GilbeRT MJ, GoodRICH JM, RIDDELL SR. Recovery of HLA-restricted cytomegalovirus (CMV)-specific T-cell responses after allogenic bone marrow transplant: correlation with CMV disease and effect of ganciclovir prophylaxis. Blood 1994; 83: 1971-1979.

67. Prentice HG, Gluckman E, Powles RL, LuUngman P, Milpied N, Camara R, Mandelu $F$ et al. Longterm survival in allogeneic bone marrow 
transplant recipients following acyclovir prophylaxis for CMV infection. The European Acyclovir for CMV Prophylaxis Study Group. Bone Marrow Transplant 1997; 19: 129-133.

68. Prentice HG, Gluckman E, Powles RL, Luungman P, Milpied N, Fernandez Ranada JM, MaNDELLI F et al. Impact of long-term acyclovir on cytomegalovirus infection and survival after allogeneic bone marrow transplantation. European Acyclovir for CMV Prophylaxis Study Group. Lancet 1994; 343: 749-753.

69. Luungman P, De la Camara R, Milpied N, Volin L, RusSell CA, CRISP A, WebSTer A et al. Randomized study of valacyclovir as prophylaxis against cytomegalovirus reactivation in recipients of allogeneic bone marrow transplants. Blood 2002; 99: 3050-3056.

70. Winston DJ, Yeager AM, ChandRaseKar PH, Snydman DR, Petersen FB, Territo MC et al. Valacyclovir Cytomegalovirus Study Group. Randomized comparison of oral valaciclovir and intravenous ganciclovir for prevention of cytomegalovirus disease after allogeneic bone marrow transplantation. Clin Infect Dis 2003; 36: 749-758.

71. Reusser P, Einsele H, LeE J, Volin L, Rovira M, ENGELHARD D et al. Randomized multicenter trial of foscarnet versus ganciclovir for preemptive therapy of cytomegalovirus infection after allogeneic stem cell transplantation. Blood 2002; 99: 1159-1164.

72. Mattes FM, Hainsworth EG, Geretti AM, NebBiA G, Prentice G, Potter M et al. A randomized, controlled trial comparing ganciclovir to ganciclovir plus foscarnet (each at half dose) for preemptive therapy of cytomegalovirus infection in transplant patients. J Infect Dis 2004; 189: 1355-1361

73. FORMAN SJ, ZAIA JA. Treatment and prevention of cytomegalovirus pneumonia after bone marrow transplantation: where do we stand? Blood 1994; 83: 2392-2398

74. Luungman P, Deliliers G, Platzbecker U, Mathes-Martin S, Bacigalupo A, Einsele $\mathrm{H}$ et al. Cidofovir for cytomegalovirus infection and disease in allogeneic stem cell transplant recipients. Blood 2001; 97; 388-392

75. ANDERSON KP, Fox MC, Brown-Driver V, MARTIN MJ, AzAD RF. Inhibition of human cytomegalovirus immediateearly gene expression by an antisense oligonucleotide complementary to immediateearly RNA. Antimicrob Agents Chemother 1996; 40: 2004-2011.

76. Hodson EM, Jones CA, Webster AC, Strippoli GF, BARCLAY PG, KABLE K et al. Antiviral medications to prevent cytomegalovirus disease and early death in recipients of solid-organ trans- plants: a systematic review of randomised controlled trials. Lancet 2005; 365: 2105

77. Falagas ME, Snydman DR, George MJ, Werner B, RUTHAZER R, GRIFFITH J et al. Incidence and predictor of CMV pneumonia in orthotopic liver transplant recipients. Transplantation 1996; 62: 1716-1720.

78. Kirklin JK, Naftel DC, Levine TB, Bourge RC, Pelletier GB, O'Donnell J et al. CMV after heart transplantation. Risk factors for infection and death: a multiinstitutional study. J Heart Lung Transplant 1994; 13: 394-404.

79. Calhoon JH, Nichols L, Davis R, Bryant CL, Levine SM, Zamora CA. Single lung transplantation. Factors in postoperative cytomegalovirus infection. J Thorac Cardiovasc Surg 1992; 103: 21-25.

80. Manez R, Kusne S, Green M, Abu-Elmagd K, IRISH W, REYES J et al. Incidence and risk factors associated with the development of CMV disease after intestinal transplantation. Transplantation 1995; 59: 1010-1014.

81. Kaufman DB, Leventhal JR, Gallon LG, Parker MA, KOFFron AJ, FrYER JP et al. Risk factors and impact of CMV disease in simultaneous pancreas-kidney transplantation. Transplantation 2001; 72: 1940-1945.

82. Torre-Cisneros J, Fortun J, Aguado JM, DE LA Camara R, Cisneros JM, Gavalda J et al. Consensus document from GESITRA-SEIMC on the prevention and treatment of cytomegalovirus infection in transplanted patients. Enferm Infecc Microbiol Clin 2005; 23: 424-437.

83. Bernabeu-Wittel M, Naranjo M, Cisneros JM, Canas E, Gentil MA, Algarra G et al. Infections in renal transplant recipients receiving mycophenolate versus azathioprine-based Inmunosupression. Eur J Clin Microbio1 Infec Dis 2002; 21: 173-180. 35.

84. Chemaly RF, Yen-Lieberman B, Castilla EA, Reilly A, Arrigain S, FARver C et al. Correlation between viral loads of cytomegalovirus in blood and bronchoalveolar lavage specimens from lung transplant recipients determined by histology and immunohistochemistry. J Clin Microbiol 2004; 42: 2168-2172.

85. Desjardin JA, Cho E, Supran S, Gibbons L, WERNER BG, SNYDMAN DR. Association of human herpesvirus 6 reactivation with severe cytomegalovirus-associated disease in orthotopic liver transplant recipients. Clin Infect Dis 2001; 33: 1358-1362

86. Pescovitz MD, Rabkin J, Merion RM, Paya CV, Pirsch J, FREEMAN RB et al. Valganciclovir results in improved oral absorption of ganciclovir in liver transplant recipients. Antimicrob Agents Chemother 2000; 44: 2811-2815. 
87. Paya C, Humar A, Dominguez E, Washburn K, Blumberg E, AleXANDer B et al. Efficacy and safety of valganciclovir vs. Oral ganciclovir for prevention of cytomegalovirus disease in solid organ transplant recipients. Am J Transplant 2004; 4: 611-620.

88. Kletzmayr J, KreuzWieser E, Watkins-Riedel T, Berlakovich G, Kovarik J, Klauser R. Longterm oral ganciclovir prophylaxis for prevention of cytomegalovirus infection and disease in cytomegalovirus high-risk renal transplant recipients [In Process Citation]. Transplantation 2000; 70: 1174.

89. Flechner SM, Avery RK, Fisher R, MastroianNI BA, PAPAJCIK DA, O’ MALlEy KJ et al. A randomized prospective controlled trial of acyclovir versus oral ganciclovir for cytomegalovirus prophylaxis in high-risk kidney transplant recipients. Transplantation 1998; 66: 1682.

90. Winston DJ, BusuTTIL RW. Randomized controlled trial of oral ganciclovir versus oral acyclovir after induction with intravenous ganciclovir for long-term prophylaxis of cytomegalovirus disease in cytomegalovirusseropositive liver transplant patients. Transplantation 2003; 75: 229-233.

91. Gane E, Saliba F, Valdecasas GJ, O`Grady J, Pescovitz MD, Lyman S et al. Randomised trial of efficacy and safety of oral ganciclovir in the prevention of cytomegalovirus disease in liver-transplant recipients. The Oral Ganciclovir International Transplantation Study Group. Lancet 1997; 350: 1729.

92. Winston DJ, BusuTtiL RW. Randomized controlled trial of sequential intravenous and oral ganciclovir versus prolonged intravenous ganciclovir for long-term prophylaxis of cytomegalovirus disease in high-risk cytomegalovirus-seronegative liver transplant recipients with cytomegalovirusseropositive donors. Transplantation 2004; 77: 305-308.

93. RAYMUND RR. Management of CMV infection and disease in transplant patients. Herpes 2004; 11: 77-86.

94. Knight DA, Hejmanowski AQ, Dierksheide JE, Williams JW, Chong AS, Waldman WJ. Inhibition of herpes simplex virus type 1 by the experimental immunosuppressive agent leflunomide. Transplantation 2001; 71: 170.

95. WALdMAN WJ, KNight DA, LuRAin NS, MilleR DM, SEDmaK DD, Williams JW et al. Novel mechanism of inhibition of cytomegalovirus by the experimental immunosuppressive agent leflunomide. Transplantation 1999; 68: 814 .
96. John GT, Manivannan J, Chandy S, Peter S, JACOB CK. Leflunomide therapy for cytomegalovirus disease in renal allograft recepients. Transplantation 2004; 77: 1460.

97. Strippoli GF, Hodson EM, Jones CJ, Craig JC. Pre-emptive treatment for cytomegalovirus viraemia to prevent cytomegalovirus disease in solid organ transplant recipients. Cochrane Darabase Syst Rev 2006; 25: CD005133.

98. Paya CV, Wilson JA, Espy MJ, Sia IG, DeBernarDI MJ, SMith TF et al. Pre-emptive use of ganciclovir to prevent cytomegalovirus infection in liver transplant patients: A randomized, placebo-controlled trial. J Infect Dis 2002; 185: 854-860.

99. Hebart H, Kanz L, Jahn G, Einsele H. Management of cytomegalovirus infection after solid-organ or stem-cell transplantation. Current guidelines and future prospects. Drugs 1998; 55: 59-72.

100. Mylonakis E, Kallas WM, Fishman JA. Combination antiviral therapy for ganciclovirresistant cytomegalovirus infection in solid-organ transplant recipients. Clin Infect Dis 2002; 34: 1337-1341.

101. Babel N, Gabdrakhmanova L, Juergensen JS, Eibl N, Hoerstrup J, Hammer M et al. Treatment of cytomegalovirus disease with valganciclovir in renal transplant recipients: A single center experience. Transplantation 2004; 78: 283-285.

102. Smith IL, Cherrington JM, Jiles RE, Fuller MD, FreEMAN WR, SPECtor SA. High-level resistance of cytomegalovirus to ganciclovir is associated with alterations in both the UL97 and DNA Polymerase genes. J Infect Dis 1997; 176: 69-77.

103. Sullivan JL, Woda BA, Herrod HG, KoH G, RIVARA FP, MuldER C. Epstein-Barr virus associated hemophagocytic symdrome: Virological and immunopathological studies. Blood 1985; 65: 1097.

104. Khatri VP, Baiocchi RA, Peng R, Oberkircher AR, Dolce JM, Ward PM et al. Endogenous $\mathrm{CD} 8+\mathrm{T}$ cell expansion during regression of monoclonal EBV-associated post-transplant lymphoproliferative disorder. J Immunol 1999; 163: 500-506.

105. Milpied N, Vasseur B, Parquet N, Garnier JL, Antoine C, Quartier P et al. Humanized antiCD20 monoclonal antibody (Rituximab) in post transplant B-lymphoprolifetaive disorder: a retrospective analysis of 32 patients. Ann Oncol 2000; 11: 113-116.

106. Haddad E, Paczesny S, Leblond V, Seigneurin JM, STERn M, ACHKAR A et al. Treatment of B- 
lymphoproliferative disorder with a monoclonal anti-interleukin-6 antibody in 12 patients: a multicenter phase 1-2 clinical trial. Blood 2001; 97: 1590-1597.

107. Comoli P, Labirio M, Basso S, Baldanti F, Grossi $\mathrm{P}$, FuRIONE $\mathrm{M}$ et al. Infusion of autologous Epstein-Barr virus (EBV)-specific cytotoxic T cells for prevention of EBV-related lymphoproliferative disorder in solid organ transplant recipients with evidence of active virus replication. Blood 2002; 99: 2592-2598.

108. British Society for Antimicrobial Chemotherapy Working Party on Antiviral Therapy. Manaegement of herpes virus infections following transplantation. J Antimicrob Chemother 2000; 45: 729-748.

109. Broyer M, Tete MJ, Guest G, Gagnadoux MF, Rouzioux C. Varicella and zóster in children aftter kidney transplantation: long term results of vaccination. Pediatrics 1997; 99: 35-39.

110. Lizasoain M, DE la SeRna J. Infecciones por virus en el trasplante de precursores hematopoyéticos. En: Infecciones en pacientes trasplantados. Aguado JM, ed. $2^{\text {a }}$ ed. Madrid, Elsevier, 2004; 311-342.

111. Meyers J, Wade J,Shepp D, Newton B. Acyclovir treatment of VZV infection in the compromised host. Transplantation 1984; 37: 571-574.

112. Sullivan KM, Dykewicz CA, Longworth DL, BoeckH M, Baden LR, Rubin RH et al. Preventing opportunistic infections after hematopoietic stem cell transplantation: the Centers for Disease Control and Prevention, Infectious Diseases Society of America, and American Society for Blood and Marrow Transplantation Practice Guidelines and beyond. Hematology 2001; 1: 392-421.

113. Langston AA, Redei I, Caliendo AM, Somani J, HuTCHERSON D, LONIAL S et al. Development of drug-resistant herpes simplex virus infection after haploidentical hematopoietic progenitor cell transplantation. Blood 2002; 99: 1085-1088.

114. Jacobs F, Knoop C, Brancart F, Gilot P, MerLOT C, BYL B et al. Human herpesvirus-6 infection after lung and heart-lung transplantation: a prospective longitudinal study. Transplantation 2003; 75: 1996-2001.

115. Benito M, Moreno A, Pumarola T, Marcos MA. Virus del herpes humano 6 y 7 en receptores de trasplantes. Enferm Infecc Microbiol Clin 2003; 21: 424-432.

116. LaUtenschlager I, LapPalainen M, KinNAVUORI $\mathrm{K}$, Suni J, HöcKeRstedT K. CMV infection is usually associated with concurrent HHV-6 and HHV-7 antigenemia in liver transplant patients. J Clin Virol 2002; 25: 57-56.

117. KI CS, KIm IS, Kim JW, LeE NY, KIm SH, LEE KW et al. Incidence and clinical significance of human parvovirus B19 infection in kidney transplant recipients. Clin Transplant 2005; 19: 751-755.

118. Egbuna O, Zand MS, Arbini A, Menegus M, TayLOR J. Cluster of parvovirus B19 infections in renal transplant recipients: a prospective case series and review of the literature. Am J Transplant 2006; 6: 225-231.

119. Edvarson VO, Flynn JT, Deforest A, KaISER BA, Schulman SL, Bradley A et al. Effective immunization against influenza in pediatric renal transplantation recipients. Clin Transplant 1996; 10: 556-560.

120. Jones RN, Fritsche TR, SAdER HS, Goldstein BP. Antimicrobial spectrum and potency of dalbavancin tested against clinical isolates from Europe and North America (2003): initial results from an international surveillance protocol. J Chemother 2005; 17: 593600.

121. Morosi S, Francisci D, Baldelli F. A case of rhombencephalitis caused by Listeria monocytogenes successfully treated with linezolid. J Infect 2006; 52: e72-5. Epub 2005.

122. Piper KE, Steckelberg JM, Patel R. In vitro activity of daptomycin against clinical isolates of Gram-positive bacteria. J Infect Chemother 2005; 11:207-9.

123. Hof H, Nichterlein T, KRetschmar M. Management of listeriosis. Clin Microbiol Rev 1997; 10: 345-357.

124. Lewis KE, Veden P, Wooster SL, Rees J, HarriSON GA. Multi-system Infection with Nocardia farcinica-therapy with linezolid and minocycline. J Infect 2003; 46: 199-202.

125. GoOdman JL, Winston DJ, GREenFIELD RA, Chandrasekar PH, Fox B, Kaizer $\mathrm{H}$ et al. A controlled trial of fluconazole to prevent fungal infections in patients undergoing bone marrow transplantation. N Engl J Med 1992; 326: 845-851.

126. Marr KA, Seidel K, Slavin MA, Bowden RA, Schoch HG, Flowers MF et al. Prolonged fluconazole prophylaxis is associated with persistent protection against candidiasisrelated death in allogeneic marrow transplant recipients: long-term follow-up of a randomized, placebo-controlled trial. Blood 2000; 96:2055-61.

127. MacMillan ML, Goodman JL, DeFor TE, WeisDORF DL. Fluconazole to prevent yeast infections in bone marrow transplantation 
patients: A randomized trial of high versus reduced dose and determination of the value of maintenance therapy. Am J Med 2002; 112: 369-379.

128.Guidelines for preventing opportunistic infections among hematopoietic stem cell transplant recipients. Biol Blood Marrow Transplant 2000; 6:659713, 715, 717-727, 729-733.

129. Marr KA, Crippa F, Leisenring W, Hoyle M, BoECKH M, BALAJEE SA et al. Itraconazole versus fluconazole for prevention og fungal infections in patients receiving allogenic stem cell transplants. Blood 2004; 103: 1527-1533.

130. VAN BuriK JA, RATANATHARATHORN V, Stepan DE, Miller CB, Lipton JH, Vesole DH et al. Micafungin versus fluconazole for prophylaxis against invasive fungal infections during neutropenia in patients undergoing hematopoietic stem cell transplantation. Clin Infect Dis 2004; 39: 1407-1416.

131. Rousey SR, Russler S, Gottlieb M, Ash RC. Low-dose amphotericin B prophylaxis against invasive Aspergillus infections in allogeneic marrow transplantation. Am J Med 1991; 91: 484.

132. O'Donnell M, Schmidt GM, Tegtmeier BR, FAUCETt C, FAEHY JL, Ito J et al. Prediction of systemic fungal infection in allogeneic marrow recipients: Impact of amphotericin prophylaxis in high-risk patients. J Clin Oncol 1994; $12: 827$.

133. Uzun O, AnAISSIE EJ. Antifungal prophylaxis in patients with hematologic malignancies: a reappraisal. Blood 1995; 86: 2063.

134. Playford EG, Webster AC, Sorell TC, Craig JC. Antifungal agents for preventing fungal infections in solid organ transplant recipi- ents. Cochrane Darabase Syst Rev 2004; 3: CD004291.

135. Drew RH, Dodds Ashley E, Benjamin DK JR, Duane Davis R, Palmer SM, Perfect JR. Comparative safety of amphotericin B lipid complex and amphotericin B deoxycholate as aerosolized antifungal prophylaxis in lungtransplant recipients. Transplantation 2004; 77: 232-237.

136. Gavaldá J, López P, Martín MT, Gomis X, RAMírez JL, PAhisSA A. Eficacia de la anfotericina B liposomal nebulizada en el tratamiento de la aspergilosis pulmonar experimental. Enferm Infecc Microbiol Clin 2004; 22: 126.

137. Hamacher J, Spiliopoulos A, Kurt AM, Nicod LP. Pre-emptive therapy with azoles in lung transplant patients. Geneva Lung Transplantation Group. Eur Respir J 1999; 13: 180.

138. Minari A, Husni R, Avery RK, Longworth DL, DECAMP M, BERTIN M et al. The incidence of invasive aspergillosis among solid organ transplant recipients and implications for prophylaxis in lung transplants. Transpl Infect Dis 2002; 4: 195.

139. FISHMAN JA. Prevention of infection caused by Pneumocystis carinii in transplant recipients. Clin Infect Dis 2001; 33:1397-405.

140. Gordon SM, LaRosa SP, Kalmadi S, Arroliga AC, Avery RK, Truesdell-LaRosa L et al. Should prophylaxis for Pneumocystis carinii pneumonia in solid organ transplant recipients ever be discontinued? Clin Infect Dis 1999; 28: 240.

141. Gurguí, M. Recomendaciones de vacunación en pacientes adultos sometidos a trasplante de órgano sólido (documento interno). SEIMC, 2006. 
